BNL 65233

Informal Report

\title{
INTEGRITY EVALUATION OF LOWER THERMAL SHIELD UNDER EXPOSURE TO HFBR ENVIRONMENT
}

Mumtaz Kassir, John Weeks and Kamal Bandyopadhyay

Consultant: Paul Shewmon, Professor, Ohio State University

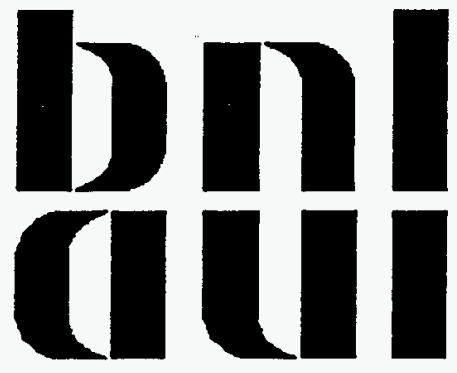

RECENVRD

APR 0 畧 1958

OSTI

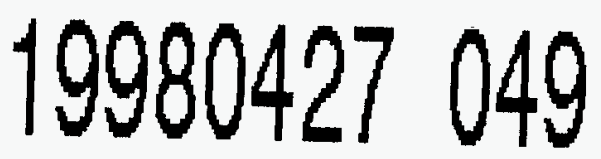

January 1998

DEPARTMENT OF ADVANCED TECHNOLOGY

BROOKHAVEN NATIONAL LABORATORY, ASSOCIATED UNIVERSITIES, INC.

UPTON, NEW YORK 11973-5000

UNITED STATES DEPARTMENT OF ENERGY

CONTRACT NO. DE-AC02-76CH00016

[DTC QUALTTY IISSPEUTHE 
This report was prepared as an acoount of work sponeored by an agency of the United States Government. Neither the United States Government nor any agency thereof, nor any of their employees, or any of their contractors, subcontractors, or their employees, makes any warrantee, expressed or implied, or assumes any legal liabilities or responsibility for the acciracy, completeness, or usefulness of an information, apparatus, product, or process disclosed, or represents that its use would not infringe privately owned rights. Reference herein to any specific commercial product, process or service by trade name, trademark, manufacturer, or otherwise, does not necessarily constitute of imply its endorsement, recommendation, or favoring by the United States Government or any agency, contractor, or subcontractor thereof. The views and opinions of authors expressed herein do not necessarily state or reflect those of the United States Government or any agency contractor or subcontractor thereof. 
BNI- 65233

Informa1 Report

UC-504

UC-506

\section{INTEGRITY EVALUATION OF LOWER THERMAL SHIELD UNDER EXPOSURE TO HFBR ENVIRONMENT}

Mumtaz Kassir, John Weeks and Kamal Bandyopadhyay

Consultant: Paul Shewmon, Professor, Ohio State University

January 1998

DISTRIBUTION OF THIS DOCUMENT IS UNLMITED

ENGINEERING TECHNOLOGY DIVISION

DEPARTMENT OF ADVANCED TECHNOLOGY

BROOKHA VEN NATIONAL LABORATORY, ASSOCIATED UNIVERSITIES, INC. UPTON, NEW YORK 1973-5000

Prepared for the

Office of Energy Research

UNITED STATES DEPARTMENT OF ENERGY, WASHINGTON, D.C.

CONTRACT NO. DE-AC02-76CH00016 


\begin{abstract}
The effects of exposure to the HFBR environment on the carbon steel in the HFBR lower thermal shield were evaluated. Corrosion was found to be a non-significant degradation process. Radiation embrittlement has occurred; portions of the plate closest to the reactor are currently operating in the lower-shelf region of the Charpy impact curve (i.e., below the fracture toughness transition temperature). In this region, the effects of radiation on the mechanical properties of carbon steel are believed to have been saturated, so that no further deterioration is anticipated. A fracture toughness analysis shows that a large factor of safety $(>1.5)$ exists against propagation of credible hypothetical flaws. Therefore, the existing lower thermal shield structure is suitable for continued operation of the HFBR.
\end{abstract}




\section{TABLE OF CONTENTS}

Page

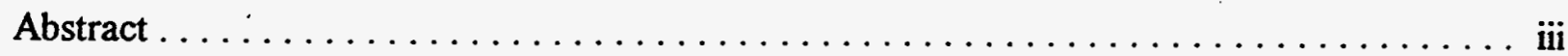

List of Figures $\ldots \ldots \ldots \ldots \ldots \ldots \ldots \ldots \ldots \ldots \ldots \ldots \ldots \ldots \ldots \ldots \ldots \ldots \ldots \ldots \ldots$

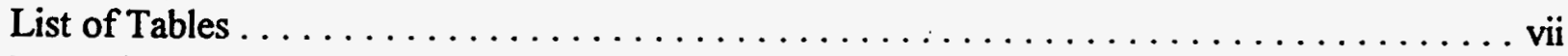

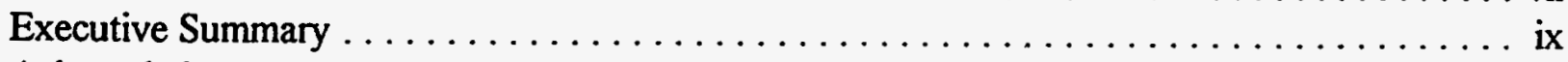

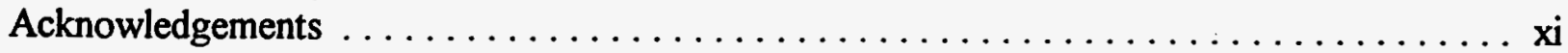

1. INTRODUCTION $\ldots \ldots \ldots \ldots \ldots \ldots \ldots \ldots \ldots \ldots \ldots \ldots \ldots \ldots \ldots$

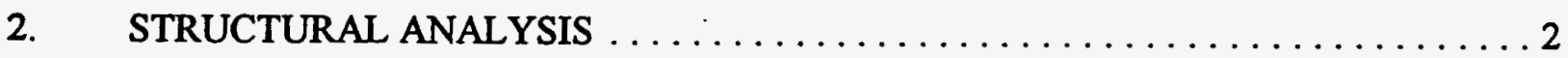

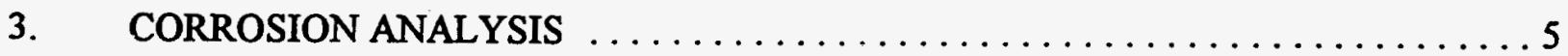

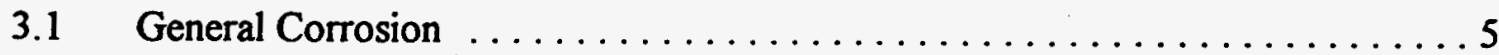

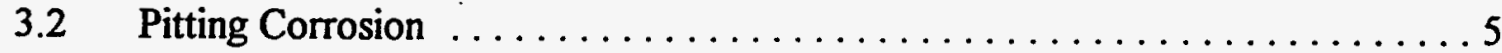

3.3 Erosion/Corrosion . . . . . . . . . . . . . . . . . . . . . . . . 5

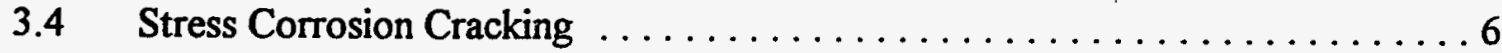

3.5 Corrosion Concerns During Extended Shutdown $\ldots \ldots \ldots \ldots \ldots \ldots \ldots 6$

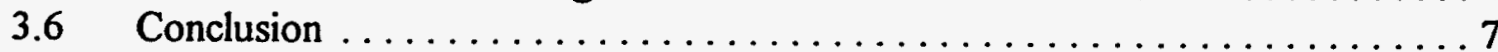

4. RADIATION EFFECTS ANALYSIS $\ldots \ldots \ldots \ldots \ldots \ldots \ldots \ldots \ldots \ldots$

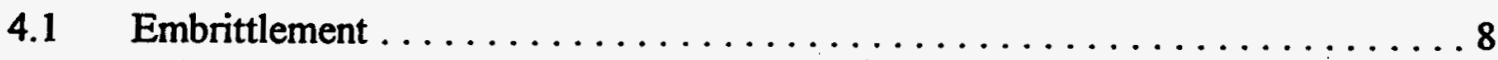

4.2 Azimuthal Variations in Fluence and Embrittlement $\ldots \ldots \ldots \ldots \ldots \ldots \ldots$

4.3 Radiation Creep ................................. 11

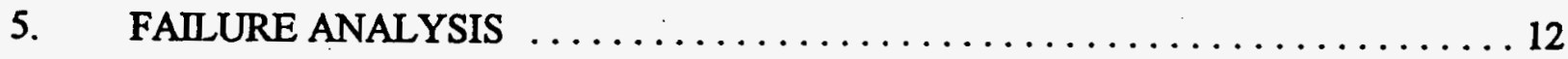

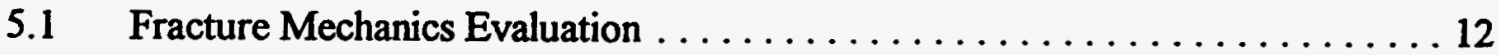

5.1.1 Region Around Beam Tube Openings $\ldots \ldots \ldots \ldots \ldots \ldots \ldots \ldots \ldots$

5.1.2 Region Near the Longitudinal Weld .................... 17

5.1.3 Regions Near the Welds at the Top of the Lower Thermal Shield .... 19

6. CONCLUSIONS AND RECOMMENDATIONS $\ldots \ldots \ldots \ldots \ldots \ldots \ldots \ldots \ldots \ldots$

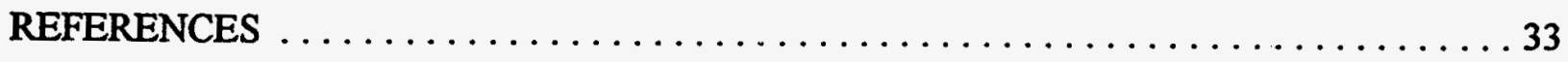

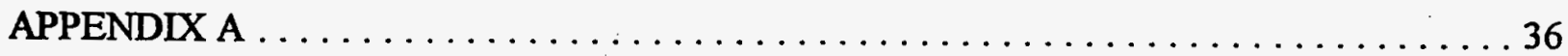




\section{LIST OF FIGURES}

$\underline{\text { Page }}$

Figure $2.1 \quad$ Thermal Shield $\ldots \ldots \ldots \ldots \ldots \ldots \ldots \ldots \ldots \ldots \ldots \ldots \ldots \ldots$

Figure 5.1 Lower Bound $\mathrm{K}_{\mathrm{lc}}$ and $\mathrm{K}_{\mathrm{la}}$ Test Data for Carbon Steel (ASME Code) $\ldots \ldots 20$

Figure 5.2 A Quarter-Elliptical Surface Crack at a Beam Tube Opening $\ldots \ldots \ldots \ldots 21$

Figure 5.3 A Semi-Elliptical Surface Crack in a Vertical Plane Near a Beam Tube

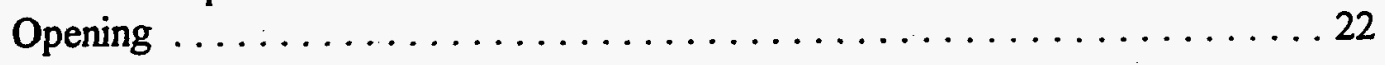

Figure 5.4 A Semi-Elliptical Circumferential Crack in the HAZ of the Longitudinal

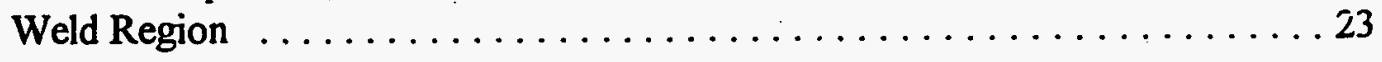

Figure 5.5 A Two Dimensional Crack Between Two V-Grooves in a Weld Butt

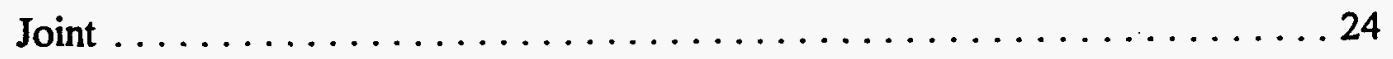




\section{LIST OF TABLES}

\section{$\underline{\text { Page }}$}

3.1 Operating Parameters of the HFBR Thermal Shield Coolant $\ldots \ldots \ldots \ldots \ldots \ldots$

4.1 Embrittlement of Inner Plate of the HFBR Thermal Shield $\ldots \ldots \ldots \ldots \ldots$

4.2 Radiation Effects Parameters for the HFBR-TS $\ldots \ldots \ldots \ldots \ldots \ldots \ldots \ldots \ldots$

5.1 Stress Intensity Factors $\left(\mathrm{K}_{1}-\mathrm{ksi} \sqrt{\mathrm{in}}\right)$ for Hypothetical Quarter-Elliptical Surface Cracks Near Beam Tube Opening (Residual Stress $S=0$ ) $\ldots \ldots \ldots \ldots \ldots 25$

5.2 Stress Intensity Factors $\left(\mathrm{K}_{1}-\mathrm{ksi} \sqrt{\mathrm{in}}\right)$ for Hypothetical Quarter-Elliptical Surface Cracks Near Beam Tube Opening (Residual Stress $S=15$ ksi) . . . . . . . . 26

5.3 Stress Intensity Factors $\left(\mathrm{K}_{1}-\mathrm{ksi} \sqrt{ } \mathrm{in}\right)$ for Hypothetical Quarter-Elliptical Surface Cracks Near Beam Tube Opening (Residual Stress $S=25$ ksi) . . . . . . . . . . 27

5.4 Stress Intensity Factors $\left(\mathrm{K}_{1}-\mathrm{ksi} \sqrt{\mathrm{in}}\right)$ for Hypothetical Semi-Elliptical Axial Cracks Near Beam Tube Opening

5.5 Stress Intensity Factors $\left(\mathrm{K}_{1}-\mathrm{ksi} \sqrt{\mathrm{in}}\right)$ for Hypothetical Semi-Elliptical Circumferential Crack Near Longitudinal (Vertical) Weld Region . . . . . . . . . . . . . . . . 29

5.6 Stress Intensity Factors $\left(\mathrm{K}_{1}-\mathrm{ksi} \sqrt{\mathrm{in}}\right)$ for a Two-Dimensional Crack Between Two

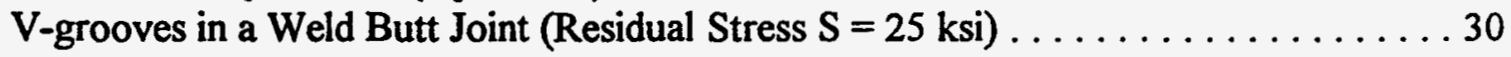

5.7 Stress Intensity Factors $\left(\mathrm{K}_{1}-\mathrm{ksi} \sqrt{\mathrm{in}}\right)$ for an Axial Semi-Elliptical Crack Near the Top Welds 


\section{EXECUTIVE SUMMARY}

\section{ES-1 Introduction}

The High-Flux Beam Reactor (HFBR) at Brookhaven National Laboratory (BNL) began operation in 1965. The lower thermal shield is composed of a series of concentric steel cylinders, with cooling water between the innermost cylinders, and a shielding layer of lead between the outer cylinders closest to the concrete biological shield. The primary function of the lower thermal shield is to protect the surrounding concrete biological shield from overheating. It also provides support for the combined weight of the upper thermal shield and the reactor vessel. Recently, as part of the proposed HFBR Improvement Project, a question was raised regarding continued reliability of the lower thermal shieid in its operating environment. The primary concern with the lower thermal shield is radiation-induced embrittlement (loss of fracture toughness) of the carbon steel from which it is made. This loss reduces the ability of the material to resist propagation of cracks that might exist in the structure. Crack propagation through the innermost cylinder could cause cooling water leakage into the cavity around the vessel. Although such leakage does not create a safety concern, it could lead to an extended shutdown of the reactor while mitigating measures are implemented. Because of its exposure to high neutron and gamma ray fluxes in the region of the lower thermal shield beam tube sleeves and innermost cylindrical steel plates, the lower thermal shield has been evaluated for its susceptibility to cracking. This report presents the integrity evaluation of the lower thermal shield under the influence of the environment present in the HFBR.

\section{ES-2 HFBR Environment and Material Degradation}

In its service life, the lower thermal shield is subjected to a temperature fluctuation of $68^{\circ} \mathrm{F}$ $\left(20^{\circ} \mathrm{C}\right)$ to $140^{\circ} \mathrm{F}\left(60^{\circ} \mathrm{C}\right), 117^{\circ} \mathrm{F}\left(47^{\circ} \mathrm{C}\right)$ being the normal operating temperature. The operating pressure of the coolant water that the lower thermal shield is exposed to is 16 psi. In the region of the lower thermal shield anticipated to be the most embrittled (i.e., the connections of the innermost cylinder to the beam tubes), the structural analysis shows a maximum stress of about $10 \mathrm{ksi}$. The majority of this stress is due to thermal and, to a lesser extent, pressure effects. The maximum irradiation fluence levels near the thermal shield beam tube connections are estimated to be of the order of $5 \times 10^{18} \mathrm{n} / \mathrm{cm}^{2}$ and $2 \times 10^{21} \gamma / \mathrm{cm}^{2}$ (E $>1 \mathrm{MeV}$ in both cases). At this exposure level, the estimated nil-ductility transition temperature (NDTT) is greater than $300^{\circ} \mathrm{F}\left(149^{\circ} \mathrm{C}\right)$ and the carbon steel material around the beam tubes is operating in the lower-shelf region of the Charpy impact curve (1.e., below the fracture-toughness transition temperature); in this region, the effects of irradiation on the mechanical properties of the steel have largely been saturated. Therefore, the thermal shield needed to be evaluated to determine whether a crack could propagate or penetrate the material thickness under the existing physical conditions. To this end, a fracture mechanics evaluation has been performed by using the ASME Boiler and Pressure Vessel Code methodology and the results are presented in the next section. 
The water chemistry of the thermal shield coolant is controlled ( $\mathrm{pH}$ of $10-11$ ) to minimize corrosion. There has not been any indication of leakage throughout the entire service period of the thermal shield. This further supports the conclusion that the corrosion effect, if any, would be minimal. The potential for plastic instability or thermal fatigue is considered to be of no concern because of the low stress level (below yield) and the small number of startup and shutdown cycles (15-20 cycles a year).

\section{ES-3 Fracture Mechanics Evaluation}

A fracture mechanics evaluation has been performed assuming a significant loss of toughness near the beam tubes and conservatively postulating surface cracks. Based on the stresses obtained from the structural analysis, it is concluded that even in these regions the fracture toughness is much larger than that needed to resist any crack driving force. (Only the tensile stress is of concern for crack propagation.) This conclusion is also true for the major portions of the thermal shield (center and outer shell) since they have been exposed to much less radiation and have lower residual stresses due to stress relief during the pouring of the molten lead during construction. Factors of safety (the ability of the material to resist propagation of a crack vs. the actual crack driving force) have been calculated for various postulated residual stresses and surface cracks in the most highly irradiated portions of the inner shell of the thermal shield, which include the heat-affected zones of the welds around beam tube openings, the vertical seam weld, and the welds at the top of the lower shield. The combined effect (i.e., applied loadings and residual stresses) shows a large factor of safety (minimum of 1.5) against the propagation of any credible hypothetical crack. This conclusion can be reliably extrapolated to the expected lifetime of the new reactor vessel (25-30 years), since the effects of irradiation on the mechanical properties of the steel have largely been saturated.

The thermal shield longitudinal (vertical) weld in the inner cylinder is located at a region of lower flux. To be conservative, this weld has also been evaluated for a non-standard weld configuration (i.e., for existence of a possible unwelded middle portion of the plate thickness). The factors of safety are estimated to be higher than the above calculated minimum of 1.5 .

\section{ES-4 Conclusions and Recommendations}

Because the cooling water chemistry is controlled, corrosion is not a significant degradation mechanism for the thermal shield. The carbon steel material of the thermal shield has been exposed to sufficient radiation that it is operating at a temperature below the nil-ductility transition temperature in some areas. However, the fracture mechanics evaluation shows a substantial margin against brittle fracture for hypothetical surface cracks subjected to the operating and analyzed plant conditions, even with inclusion of conservative residual stresses. Since the irradiation effects on the mechanical properties in these areas are saturated and are not expected to cause any significant further degradation, the continued use of the lower thermal shield is not a concern. It is recommended, however, that caution be taken during the vessel replacement process to avoid any impact load on the lower thermal shield. 


\section{ACKNOWLEDGMENTS}

The assistance of BNL's Reactor Division staff in providing input to this analysis is gratefully acknowledged, especially the contributions of W.J. Brynda, J.R. Skonieczny, P.R. Tichler, and G. Gharabegie. The fluence calculations were performed by H. Ludewig and A.L. Aronson of BNL's Department of Advanced Technology. The work was performed under the auspices of the U.S. Department of Energy. 


\section{INTRODUCTION}

The HFBR lower thermal shield has been in the reactor since startup in 1965. It is a welded carbon steel structure that surrounds the reactor, and is located in the cavity formed by the concrete biological shield. It is composed of a series of concentric steel cylinders, with cooling water between the innermost cylinders, and a shielding layer of lead between the outer cylinders near the concrete biological shield. Its principal function is to protect the concrete biological shield from radiation damage by absorbing radiation from the reactor. The lower thermal shield (LTS) lines the reactor cavity and has holes in it opposite the beam tubes to permit passage of neutron beams to the experimental floor. The lower thermal shield is not part of the reactor coolant pressure boundary; however, it provides mechanical support for the reactor vessel. The lower thermal shield has been exposed to both neutron and gamma radiation for over 30 years. Some areas of the thermal shield may have been partially stress-relieved when molten lead, for additional gamma shielding, was cast into an inner channel of the structure during original construction, at a temperature of approximately $700^{\circ} \mathrm{F}$. However, the portions of the thermal shield closest to the reactor did not become stressrelieved by the addition of the lead, so that residual stresses from welding in this area must be assumed to be still present, as discussed below. The lower thermal shield is continuously cooled during reactor operation by a closed water system with water chemistry controlled by demineralization. There have been no known chemical upsets in this coolant over the entire period of HFBR operation. During extended shutdowns of the HFBR, the thermal shield cooling system has been activated weekly to minimize any corrosion by stagnant water.

The degradation processes that can potentially affect the integrity of the lower thermal shield during continued operation are corrosion and irradiation. Corrosion processes affect the integrity of the lower thermal shield and its usefulness for continued operation. Irradiation induces loss in ductility and degrades the material fracture toughness (i.e., the ability of the material to resist crack propagation). The degree of degradation depends on the neutron and gamma fluences, the temperature, and the sensitivity of the carbon steel. The purpose of this review is to evaluate the effects of these phenomena on the lower thermal shield at the present time and to estimate its ability to serve its design function during an additional period of 30 years of HFBR operations.

This review provides analyses of the LTS in the following areas: structural analysis (Section 2), corrosion analysis (Section 3), radiation effects analysis (Section 4), and failure analysis (Section 5). Conclusions and recommendations from this review are summarized in Section 6. 


\section{STRUCTURAL ANALYSIS}

The lower thermal shield is composed of a series of concentric steel cylinders, with cooling water between the innermost cylinders, and a shielding layer of lead between the outer cylinders near the concrete biological shield as shown in Figure 2.1. Its basic dimensions are $9 \mathrm{ft}$. 0 in. outside diameter, $7 \mathrm{ft}$. -6 in. inside diameter, and overall height of $10 \mathrm{ft}$. $-63 / 4 \mathrm{in}$. The composite wall is $9 \mathrm{in}$. thick, with 3 in. of steel plate, $1.25 \mathrm{in}$. of cooling water, and $4.75 \mathrm{in}$. of lead. The lower thermal shield weighs $110,000 \mathrm{lbs}$., of which $70,230 \mathrm{lbs}$. is due to the lead layer. It provides support for the combined weight of the upper thermal shield $(30,000 \mathrm{lbs}$.) and the reactor vessel $(45,325 \mathrm{lbs}$.). The reactor vessel is bolted to the upper thermal shield and the combined weight is transmitted to the foundations through a support ring. A 1-in. gap around the sides and bottom of the shield insures that thermal expansion is not restrained by the surrounding concrete.

The stresses in the lower thermal shield are due to the water pressure in the coolant spaces $(p=16$ psig), the combined weight of upper thermal shield and reactor vessel and contents $(75,325$ lbs.), seismic loading (ground motion Zero Period Acceleration of $0.2 \mathrm{~g}$ ), and differential thermal expansion. A detailed structural analysis of the lower thermal shield is available in Reference 2-1. The maximum induced stress due to the operating and analyzed plant conditions anywhere in the lower thermal shield is less than the yield strength of the virgin material. In this section, a simplified analysis of the stresses induced in the innermost cylinder is performed to confirm the analysis of Reference 2-1.

Since the primary concern is radiation-induced embrittlement of the material, which is carbon steel, the vulnerable component of the lower therrnal shield is its innermost cylinder. The innermost cylinder has a constant thickness of $3 / 4$ in. except in a small region at the top where the plate is thinned down to $3 / 8$ in. to allow flexibility under thermal expansion. The dead load and design basis earthquake loading contribute insignificant stresses to the innermost cylinder. The water pressure gives rise to compressive vertical $\left(\sigma_{\mathrm{v}}=\mathrm{pR} / 2 \mathrm{t}\right)$ and hoop $\left(\sigma_{\mathrm{h}}=\mathrm{pR} / \mathrm{t}\right)$ stresses of magnitudes $0.49 \mathrm{ksi}$ and $0.98 \mathrm{ksi}$, respectively. Near the top $(t=3 / 8 \mathrm{in}$.) the magnitudes of these stresses are doubled.

The steady-state thermal stresses due to differential expansion of the inner cylinder are approximated by the following formulas [Reference 2-2]: at the inner surface of the cylinder (facing the vessel):

$$
\sigma_{\text {vert. }}=\sigma_{\text {hoop }}=-E \alpha\left(T_{i}-T_{o}\right) / 2(1-v)
$$

and at the outer surface of the cylinder (the cooling water side):

$$
\sigma_{\text {vert. }}=\sigma_{\text {hoop }}=E \alpha\left(T_{i}-T_{o}\right) / 2(1-v)
$$


where $T_{i}$ and $T_{o}$ are the temperatures at the inner and outer surfaces, respectively, $\alpha$ is the coefficient of thermal expansion, and $\mathrm{E}$ and $v$ are Young's modulus and Poisson's ratio of the material.

For a temperature differential of $50^{\circ} \mathrm{F}$ between the inner and outer surfaces, and with $\mathrm{E}=$ $30 \mathrm{E} 03 \mathrm{ksi}$ and $\alpha=6.5 \mathrm{E}-06 \mathrm{in} / \mathrm{in} /{ }^{\circ} \mathrm{F}$, equations (2.1) and (2.2) result in stresses of $7 \mathrm{ksi}$ tension on the cooler surface and $7 \mathrm{ksi}$ compression on the hotter surface. It should be mentioned that these values are based on ideal cylindrical geometry and the effects of beam tube openings and constraints of other components of the lower thermal shield are neglected. These results confirm the detailed stress analysis performed by the Reactor Division. The effects of stress concentration, expansion of the lead layer, and other constraints are available in Reference 2-1. 


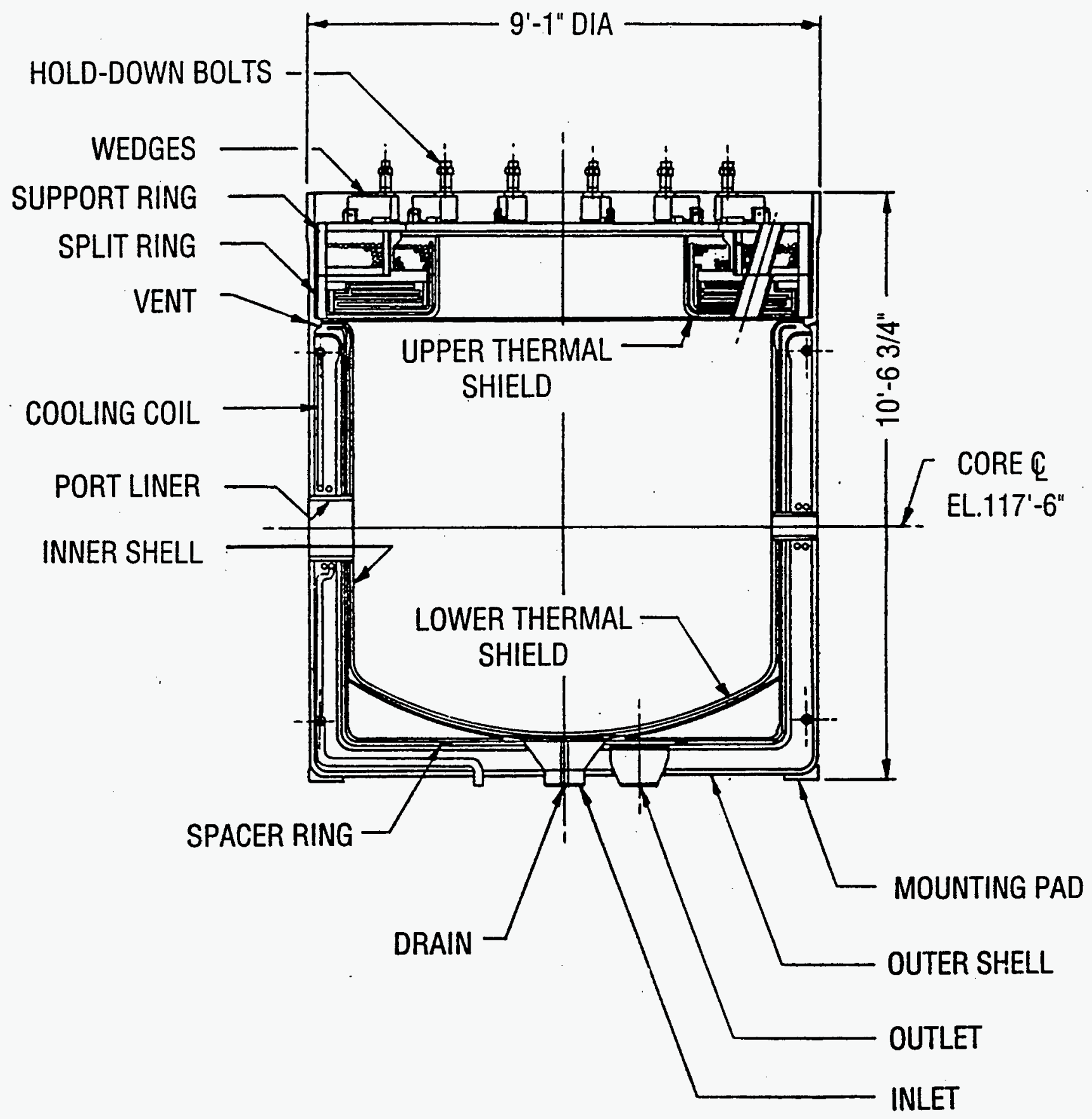

Figure 2.1 Thermal Shield 


\section{CORROSION ANALYSIS}

The integrity of the lower thermal shield and its usefulness for continued operation can be potentially affected by the following corrosion processes, each of which will be discussed in turn: general corrosion, pitting corrosion, erosion/corrosion, and stress corrosion. Coolant leakage into the reactor cavity by any of these mechanisms would be a significant operational problem, but would not affect reactor safety as long as adequate cooling of the thermal shield can be maintained.

\subsection{General Corrosion}

Table 3.1 gives the ranges of temperature, $\mathrm{pH}$, conductivity, velocity, and oxygen level in the LTS coolant that have been maintained throughout the HFBR operating history [Ref. 3-1]. Oxygen is controlled by a nitrogen sparger in the head tank of the LTS coolant system, and pH is controlled by the demineralizer beds. General corrosion rates of the lower thermal shield (LTS) plates in this controlled environment should be minimal.

The HFBR-LTS coolant system is a closed loop fabricated from carbon steel. Carbon steel will form a protective oxide under the conditions shown in Table 3.1; as a result, corrosion rates will continue to decrease with time. Initially, rates may have exceeded $1 \mathrm{mil} / \mathrm{yr}$ for a few months, but are estimated to have decreased to a rate well below $0.1 \mathrm{mil} / \mathrm{yr}$ at present [Ref. 3-2]. Consequently, the estimated maximum general corrosion has been less than 5 mils over the past 30 years, and is expected to be only 1 or 2 mils more over the next 30 years.

\subsection{Pitting Corrosion}

Pitting corrosion of carbon steel usually occurs at $\mathrm{pH}$ below 7 in the presence of oxidizing ions or oxygen and halides. Pitting is highly unlikely in clean water of the high $\mathrm{pH}$ and low oxygen concentrations given in Table. 3.1.

Even in concentrated nuclear wastes, tests have shown negligible pitting of carbon steel at $\mathrm{pH}$ $>10$ [Ref. 3-3]. During the HFBR original start-up, loose iron oxides were briefly a problem in this system, but, as the protective surface films built up with time, the problem (i.e., clogged filters and demineralizers) went away, as expected. Pitting could be a problem during extended shutdowns in stagnant coolant, especially if air has access to the water, as discussed in a subsequent paragraph.

\subsection{Erosion/Corrosion}

Erosion/corrosion of carbon steel generally involves removal of the protective oxides by their erosion or dissolution in high-velocity water. Usually, it is encountered at $\mathrm{pH}<7$, temperatures $>100^{\circ} \mathrm{C}$, and velocities $>6 \mathrm{ft} / \mathrm{sec}$ [Ref. 3-4]. The high $\mathrm{pH}$ and low temperature and velocity in the HFBR-TS coolant are all beneficial in preventing erosion/corrosion from becoming a concern. Oxygen is also beneficial; while oxygen in the coolant is kept low by nitrogen sparging, the absence 
of a reducing environment (i.e., excess hydrogen) and radiolysis of water by the gamma flux will assist in maintenance of the protective oxide film. Consequently, erosion/corrosion is not a significant aging mechanism for the thermal shield.

\subsection{Stress Corrosion Cracking}

Stress corrosion cracking (SCC) of any metal requires a combination of a susceptible material, high tensile stresses, and a corrosive environment. SCC of carbon steel should not occur in the environment given in Table 3.1; SCC-causing ions (nitrate or chlorides) are not present, and the $\mathrm{pH}$ is high. While applied stresses are low, residual stresses from welding are present, which are in many cases sufficient to initiate SCC. However, no SCC is known to have occurred (or leaks developed) in the HFBR-TS in over 30 years, and the likelihood of SCC occurring now or over the foreseeable future is extremely low, unless major changes develop in the environment and stress patterns. Proper continuation of the chemistry controls and recommended shutdown procedures will prevent future development of SCC.

Table 3.1

Operating Parameters of the HFBR Thermal Shield Coolant [Ref. 3-1]

\begin{tabular}{|c|c|}
\hline Parameter & Value \\
\hline $\begin{array}{c}\text { Temperature } \\
\text { Normal } \\
\text { Operating Range }\end{array}$ & $117^{\circ} \mathrm{F}\left(47^{\circ} \mathrm{C}\right)$ \\
\hline $\mathrm{pH}$ & $68^{\circ} \mathrm{F}-140^{\circ} \mathrm{F}\left(20-60^{\circ} \mathrm{C}\right)$ \\
\hline Conductivity & $10-11$ \\
\hline Velocity & $175-220 \mu$ mho/cm \\
\hline Oxygen & $1.56 \mathrm{ft} / \mathrm{sec}$, maximum \\
\hline
\end{tabular}

\subsection{Corrosion Concerns During Extended Shutdown}

During extended shutdowns (lasting more than one or two weeks), corrosion of the thermal shield could develop if water quality and flow are not periodically maintained. Stagnant water exposed to the air can develop in areas of lower $\mathrm{pH}$ where pitting, crevice corrosion, or stress corrosion cracking could initiate. The Reactor Division has stated that, during the last extended shutdown period (1989 - 1991), the coolant flow and chemical control system were activated weekly to maintain water purity in the thermal shield. This is good practice and should continue to be implemented during any future extended shutdowns, including planned and unscheduled outages. The Reactor Division should formalize this program as part of their shutdown maintenance procedures. 


\subsection{Conclusion}

Environmental factors that might accelerate corrosion and stress corrosion cracking of the carbon steel would be a drop in $\mathrm{pH}$ to below 9, and introduction of anions or cations that could cause pitting corrosion (most notably carbonates, chloride, or copper ions) [Ref. 3-2]. Neither of these conditions is known to have occurred in the HFBR-TS cooling system and adequate controls are in place to prevent them from developing in the future. Consequently, none of the possible corrosion processes, described above, should lead to leakage or failure of the thermal shield over the foreseeable future. 


\section{RADIATION EFFECTS ANALYSIS}

The carbon steel thermal shield material can be affected by radiation in two principal ways: embrittlement and radiation creep. Theses effects are opposite: embrittlement results from displacement of atoms by high energy neutrons and gammas and causes reduction in fracture toughness (ability of the material to resist propagation of cracks) and build-up of internal stresses, while radiation creep may cause local reduction in operational, residual, or irradiation-induced stresses. Both phenomena are discussed below as they may potentially affect the HFBR thermal shield.

\subsection{Embrittlement}

Embrittlement of carbon steel by irradiation has traditionally been attributed to displacement of the atoms in the steel by fast neutrons. For the purpose of this report, embrittlement refers to loss of fracture toughness of the steel or loss in the material's ability to resist crack propagation. The embrittlement is measured in terms of a nil-ductility transition temperature (NDTT) at which the material absorbs a given amount of impact energy in a standard Charpy impact test. In 1968, Chow, et al. [Ref. 4-1] reported measurements of the embrittlement of the inner and outer plate material of the HFBR-TS following irradiation of specimens of these plates in the BGRR to a fluence of 5.5. $x$ $10^{18} \mathrm{n} / \mathrm{cm}^{2}, \mathrm{E}>1 \mathrm{MeV}$, which is close to the fast neutron fluence received in the highest-flux areas of the inner plate at the present time $\left(4.1 \times 10^{18} \mathrm{n} / \mathrm{cm}^{2}, \mathrm{E}>1 \mathrm{MeV}\right)$. These results are given in Table 4.1.

Because of the unexpectedly large embrittlement of the HFIR vessel [Ref. 4-2], researchers at ORNL and ANL have recently been investigating the effects of other types of irradiation, notably high-energy gamma irradiation, on embrittlement of steel. Remec and Kam at Oak Ridge [Ref. 4-3] have used this argument to explain the abnormally high HFIR vessel embrittlement. In principle, the common factor that results in embrittlement is the number of displacements per atom (dpa) caused by the irradiation. A fast neutron fluence of $10^{21} \mathrm{n} / \mathrm{cm}^{2}(\mathrm{E}>1 \mathrm{MeV})$ is roughly equivalent to $1 \mathrm{dpa}$ in the steel, and the threshold for increases in nil-ductility transition temperature (NDTT) is approximately $10^{17} \mathrm{n} / \mathrm{cm}^{2}(E>1 \mathrm{MeV})$, or $10^{-4} \mathrm{dpa}$, based on high-flux reactor data. However, high energy gamma irradiation ( $E>1 \mathrm{MeV}$ ) can also produce atomic displacements; $D$. Alexander of ANL [Ref. 4-4] estimates from his research that the high energy gamma irradiation is approximately $1 \%$ as effective in producing dpa as high energy neutron irradiation, with $\mathrm{E}>1 \mathrm{MeV}$ in both cases. The total dpa from high energy neutron and gamma bombardment can thus be estimated by adding the dpa estimates from both sources. Chow et al. [Ref. 4-5] found the NDTT of the unirradiated inner plate material to be 0 to $15^{\circ} \mathrm{C}$.

Table 4.2 gives the relevant information for the HFBR-TS [Ref. 4-6]. Using the approximation, $\mathrm{dpa}_{\mathrm{r}}=0.01 \mathrm{dpa}_{\mathrm{w}}$, and converting to an equivalent neutron fluence, an equivalent fast neutron fluence of $2.4 \times 10^{19} \mathrm{n} / \mathrm{cm}^{2}(\mathrm{E}>1 \mathrm{MeV})$, or $0.024 \mathrm{dpa}$, can be used for estimating the total embrittlement of the HFBR-TS in the highest fluence regions, near the beam tube openings. 
Table 4.1 gives values of the nil-ductility transition temperature of the inner plate from BGRR irradiation. Clearly, the NDTT of the material adjacent to the beam tube holes from the fast neutron fluence alone would be well above the operating temperature of the HFBR-TS $\left(72^{\circ} \mathrm{C}\right.$, as estimated from the HFBR FSAR, Table 10.2-3) or the temperature of the LTS coolant $\left(47^{\circ} \mathrm{C}\right.$, given in Table 3.1). Adding in the effects of the gamma fluences further increases the NDTT. Chow and Jones [Refs. 4-7, 4-8] state that "the plates show about average sensitivity to radiation." Using the lowtemperature data of Steele and Hawthorne [Ref. 4-9], a neutron fluence of $2.4 \times 10^{19} \mathrm{n} / \mathrm{cm}^{2}(\mathrm{E}>1$ $\mathrm{MeV}$ ), which corresponds to the dpa estimated above from the combined effects of fast neutrons, and high-energy gammas, would cause an average shift in nil-ductility temperature of $160^{\circ} \mathrm{C}$, or a current NDTT of $160-175^{\circ} \mathrm{C}$. If, alternatively, we assume that the shift in NDTT is approximately proportional to the cube root of the fluence (or dpa) as some data suggest [Ref. 4-10], we can extrapolate Chow's result at $5.5 \times 10^{18} \mathrm{n} / \mathrm{cm}^{2}$ as follows:

$$
\delta T_{N D T T\left(2.4 \times 10^{19}\right)}=\delta T_{N D T T\left(5.5 \times 10^{18}\right)}\left(\frac{24}{5.5}\right)^{1 / 3}=170^{\circ} \mathrm{C}
$$

The current NDTT would then be $170-185^{\circ} \mathrm{C}$. Both estimates are in very good agreement, and suggest that the HFBR-LTS is currently operating more than $100^{\circ} \mathrm{C}$ below its estimated nil-ductility transition temperature in some areas, as summarized in Table 4.1. This is not a concern when the applied tensile stresses are low in the area of maximum combined fluence, and/or major flaws are known not to be present. (A fracture mechanics evaluation is presented in Section 5.)

Table 4.1

Embrittlement of Inner Plate of the HFBR Thermal Shield

\begin{tabular}{|l|c|}
\hline \multicolumn{1}{|c|}{ Condition } & 25 ft-lb Transition Temperature \\
\hline Unirradiated & $32^{\circ} \mathrm{F}-60^{\circ} \mathrm{F}\left(0^{\circ} \mathrm{C}-15^{\circ} \mathrm{C}\right)$ \\
\hline After $5.5 \times 10^{18} \mathrm{n} \mathrm{cm}^{2}$ (BGRR) & $210^{\circ} \mathrm{F}-250^{\circ} \mathrm{F}\left(99^{\circ} \mathrm{C}-121^{\circ} \mathrm{C}\right)$ \\
\hline Average Shift & $189^{\circ} \mathrm{F}\left(87^{\circ} \mathrm{C}\right)$ \\
\hline $\begin{array}{l}\text { Combined } \gamma+n \text { effect, } \\
\text { estimated from Steele and Hawthorne } \\
\text { estimated from cube-root rule and } \\
\text { BGRR data }\end{array}$ & $160^{\circ} \mathrm{C}-175^{\circ} \mathrm{C}\left(160^{\circ}\right.$ shift $)$ \\
\hline
\end{tabular}


Table 4.2

Radiation Effects Parameters for the HFBR-TS [Refs. 3-1 and 4-6]

\begin{tabular}{|c|c|c|}
\hline Flux & Fluence/MWD/cm & $\begin{array}{c}\text { Fluence @272,000 MWD } \\
\text { (August 1994) }\end{array}$ \\
\hline Neutrons, E>1 MeV & $1.5 \times 10^{13}$ & $4.1 \times 10^{18} \mathrm{n} / \mathrm{cm}^{2} \mathrm{E}>1 \mathrm{MeV}$ \\
\hline Gammas, E $>1 \mathrm{MeV}$ & $7.5 \times 10^{15}$ & $2.0 \times 10^{21} \mathrm{\gamma} / \mathrm{cm}^{2}$ \\
\hline
\end{tabular}

Two additional observations are made. First, these estimates are for embrittlement of the carbon steel plates; in most structures, the welds in the carbon steel are more sensitive to irradiation embrittlement than the plate material, especially when the structure was not stress-relieved after welding, and, welds are the locations where flaws are most likely to be present. Thus, any welds in the high combined-fluence areas.would be the most likely locations where brittle failure could initiate. Second, longitudinal seam welds (where the principal residual stresses from welding are likely to be present) are located by design away from the beam tube holes, where lower fluxes of both fast neutrons and gammas are likely to be present (see 4.2 below). The HFBR-LTS was partially stressrelieved after welding. Normal stress-relief requires a temperature of $1100^{\circ} \mathrm{F}$ for one hour or $1000^{\circ} \mathrm{F}$ for four hours [Ref. 4-11]. The heating (to $700^{\circ} \mathrm{F}$ ) for several hours that occurred during pouring liquid lead into the TS may have been sufficient to relieve approximately 50 percent of the residual stresses [Ref. 4-11]. However, the plate closest to the reactor was not stress-relieved.

Since the HFBR-LTS is operating at temperatures well below its ductile-brittle transition temperature, or in the "lower-shelf" region of the fracture toughness curve, it is highly likely that embrittlement in this (the lower-shelf) region has saturated, and that future irradiations will not have a major effect on the properties that now exist at operating temperatures. Recent work at ORNL has shown saturation in the tensile properties of carbon steel at temperatures below $100^{\circ} \mathrm{C}$ and fluences above approximately $0.02 \mathrm{dpa}$ [Refs. 4-12 and 4-13]. Thus, further damage to those properties is not likely to develop. The absence of cracks resulting from embrittlement to date implies that cracks are not likely to develop during the foreseeable future.

\subsection{Azimuthal Variations in Fluence and Embrittlement}

Both the fast $(E>1 \mathrm{MeV})$ neutron and the hard $(E>1 \mathrm{MeV})$ gamma fluxes are greatest at the beam tube openings; points between the tubes where some of the major welds in the thermal shield are located receive approximately $10 \%$ of the peak fast neutron flux and $33 \%$ of the peak hard gamma flux [Ref. 4-14]. In these areas, the "equivalent neutron fluence" would be approximately 7.4 $\mathrm{x} 10^{18}$ (as estimated above), and the shift in NDTT for the plate would be $115^{\circ} \mathrm{C}$, using the cube root extrapolation, or the estimated NDTT would be 115 to $130^{\circ} \mathrm{C}$; this is still well above the operating temperature of the LTS, and welds would be even more affected than the base metal. Consequently, the preceding discussions and conclusions are not significantly changed by considering these flux reductions. 
Recent discussions with K. Farrell of ORNL at the June, 1996 International Symposium on the Effects of Irradiation on Materials [4-15] indicate that the damage attributed to $\gamma(>1 \mathrm{MeV})$ irradiation may be less than that estimated above, but that thermal neutron damage plays a part. Farrell emphasized that the displacements from both the $\gamma$ and thermal neutron result from electrons displaced by the primary radiation, not the $\gamma$ or thermal neutrons themselves. Using the crosssections for causing atomic displacements, as determined by Farrell et al. in an attempt to explain the embrittlement of the HFIR vessel [Ref. 4-16], one obtains the following approximate relationship:

$$
1 \mathrm{n} / \mathrm{cm}^{2}(E>1 \mathrm{MeV}) \approx \frac{1}{150} \mathrm{n} / \mathrm{cm}^{2} \text { thermal } \approx \frac{1}{1000} \gamma / \mathrm{cm}^{2}(E>1 \mathrm{MeV}) \text {. }
$$

The thermal neutron flux at the welds adjacent to the H-9 tube in the LTS is $4.3 \times 10^{16}$ $\mathrm{n} / \mathrm{cm}^{2} / \mathrm{MWD}$; it drops by a factor of 2.5 at the mid-point between beam tubes [Ref. 4-6]. Using this revised relationship, the estimated dpa at $272,000 \mathrm{MWD}$ is 0.10 at the weld adjacent to the $\mathrm{H}-9$ tube, and 0.01 at the mid-point between the beam tubes. These correspond to estimated NDTT values of $295^{\circ} \mathrm{C}$ and $210^{\circ} \mathrm{C}$, respectively. Clearly, no matter which approach one uses for estimating the damage, the HFBR-LTS is operating well below the NDTT of the carbon steel plate and welds, and is in a region of the Charpy curve known as the "lower-shelf" region. Oak Ridge data [Ref. 4-12] have shown that the effects of irradiation on the tensile properties of steels in the lower shelf region are saturated at these fluences and will not deteriorate further with time.

\subsection{Radiation Creep}

Radiation creep is a phenomenon occasionally observed in highly stressed metals when neutron bombardment of the lattice causes sufficient atomic motion to cause the metal to "creep" in response to these stresses, and reduces the high residual stresses present in the structure. Radiation creep has usually been studied (in steels) at temperatures above approximately $400^{\circ} \mathrm{C}$ and at dpa $>$ 0.1. The temperature $\left(60^{\circ} \mathrm{C}\right)$ and maximum dpa (0.02) in the HFBR-TS are far below this studied environment. However, recent results at ORNL [Ref. 4-13] on austenitic and ferritic stainless steels show that radiation creep in these materials can occur at temperatures below $100^{\circ} \mathrm{C}$. Therefore, some stress-relief of the welds and their heat-affected-zones may have occurred during operation of the HFBR-TS by this mechanism. While it is impossible to quantify this effect from currently available data, the trend is such as to reduce the probability of crack propagation by either brittle fracture or stress corrosion cracking during future HFBR operations. 


\section{FAILURE ANALYSIS}

The main concern in the evaluation of the structural integrity of the lower thermal shield is radiation damage due to neutron and gamma radiation exposure which reduces the ability of the material to resist the propagation of cracks that might exist in the structure. Under normal operating conditions, the stresses in the lower shield and especially in its innermost cylinder are low. Reactor startup and shutdown consist of 15-20 cycles a year with each cycle giving rise to stresses ( $<10 \mathrm{ksi})$ not exceeding $1 / 3$ of the yield strength which indicates that thermal fatigue is not a concern. A major portion of the lower thermal shield has been significantly stress-relieved due to pouring of the hot lead during the construction process. The water-retaining innermost cylinders were welded to the lower thermal shield afterwards and were not stress-relieved. It follows that tensile residual stresses near weld regions of the innermost cylinder, which can be as high as the yield strength, when combined with tensile operating stresses may cause cracking in the affected region.

Near the heat-affected zones (HAZ) of weld regions, the most likely hypothetical flaws are semi-elliptical and/or quarter-elliptical surface cracks situated in planes normal to existing tensile fields. Thus, for the longitudinal and/or circumferential (hoop) tensile stresses in the inner shell, the semi-major axis of the hypothetical crack can be assumed along the surface of the inner cylinder and its semi-minor axis in the radial (i.e., through-thickness) direction. When subjected to both tensile and bending loadings, as in the present application, the crack driving force in the circumferential direction is lower than the corresponding force in the radial direction. It follows that the preferred crack growth direction is through the thickness of the shell which indicates leak-before-break behavior. Thus, the primary failure mode which needs to be addressed is crack formation in the innermost shell of the shield, subsequent crack penetration through the 3/4-inch plate, and eventual leakage of the cooling water into the cavity around the vessel. Although such a failure does not affect safety because no radioactive material is released, it could lead to an extended shutdown of the reactor while mitigating measures are implemented. Cracks or flaws could already exist in the critical regions of the innermost shell, or could be formed by the combined effects of tensile residual and service stresses, thermal fatigue, and the environment. Also, because of radiation damage to the material, crack extension is expected to occur mainly by cleavage (brittle fracture) and some ductile tearing. Other possible modes of failure which may potentially affect the structural vulnerability of the lower thermal shield include plastic tearing and shattering due to extreme accidental loads such as unexpected, unanalyzed seismic events and loads arising from unusual construction accidents during reactor upgrade procedures. Because the fracture toughness of the material (ability to resist crack extension) is reduced by neutron and gamma irradiation, the crack extension by cleavage and the subsequent "leak-before-break" failure is of particular interest in this evaluation. For critical hypothetical cracks, the available safety margins associated with such mode of failure require a deterministic fracture mechanics evaluation, which is presented in this section.

\subsection{Fracture Mechanics Evaluation}

The underlying premise of any fracture mechanics analysis is that fracture is caused by initiation and propagation of cracks. The cracks could be real, i.e., are known to exist in the 
component, or could be hypothetical, i.e., assumed at critical locations, and attention is focused on the stresses and strains near the crack tips. As a conservative first approximation, the crack tips are assumed sharp, i.e., mathematically modeled to have zero radii of curvature at their ends, and the two surfaces of the crack are separated by negligible distance.

In the nuclear industry, the ASME Boiler and Pressure Vessel Code [References 5-1, 5-2] recommends the use of Linear Elastic Fracture Mechanics (LEFM) for evaluating the flaw behavior of irradiated carbon steel components subjected to stresses below the yield strength of the material. The procedure, which is used to assess the acceptability of flaws that have been detected during inservice inspection and that exceed the Code allowable values, applies to ferritic materials 4-inch and greater in thickness with a specified minimum yield strength of $50 \mathrm{ksi}$ or less. The 4-inch minimum thickness is required to ensure plane strain conditions (i.e., triaxial state of stress) ahead of the crack tip. In the present application, it is proposed to use the same methodology, which should yield conservative results, for assessing the safety margins of critical hypothetical cracks in the inner shell of the shield which has thickness $t=0.75$ inch. The methodology involves considering hypothetical cracks situated in planes normal to maximum tensile stresses, calculating the stress-intensity factor $\left(\mathrm{K}_{1}\right)$ which is the crack driving force, and comparing with the fracture toughness of the material such that crack propagation takes place when $\mathrm{K}_{1}$ is equal to the fracture toughness of the irradiated material.

According to the ASME Code [Ref. 5-2], the fracture toughness is determined by two properties $K_{1 c}$ and $K_{t a}$, which represent critical values of the stress intensity factor $K_{1}$. $K_{1 c}$ is based on the lower bound of static initiation critical $K_{1}$ values while $K_{1 a}$ is based on the lower bound of crack arrest critical $K_{1}$ values. Both properties are functions of $\left(T-R T_{N D T}\right)$, where $T$ is the operating temperature and $\mathrm{RT}_{\mathrm{NDT}}$ is a reference nil-ductility temperature, and are given by the relations

$$
\begin{gathered}
K_{1 c}=33.2+20.734 \exp \left[0.02\left(T-R T_{N D T}\right)\right] \\
K_{1 a}=26.8+12.445 \exp \left[0.0145\left(T-R T_{N D T}\right)\right]
\end{gathered}
$$

where $\left(\mathrm{T}-\mathrm{RT}_{\mathrm{NDT}}\right.$ ) is measured in ${ }^{\circ} \mathrm{F}$ and $\mathrm{K}_{1 \mathrm{c}}$ and $\mathrm{K}_{1 \mathrm{~s}}$ in $\mathrm{ksi}(\mathrm{in})^{1 / 2}$. In equations (5.1) and (5.2), the indexing temperature $\mathrm{RT}_{\mathrm{NDT}}$, which is highly influenced by the radiation damage due to neutron and gamma exposure, is defined as the higher of the following: (1) The nil-ductility transition temperature (NDTT) as determined in accordance with standard ASTM procedures [Ref. 5-3]. In the dropweight test, for example, the NDTT is the temperature above which a crack running out of a notch in brittle weld bead will not propagate completely across the tension face of the test specimen; (2) $60^{\circ} \mathrm{F}$ below the minimum temperature at which the lowest of the three Charpy V-notch test results is at least $50 \mathrm{ft}-\mathrm{lb}$. Figure 5.1 represents graphical variations of equations (5.1) and (5.2). In the 
present application, an estimate of the NDTT based on the fluence level is made and used as the indexing temperature in equations (5.1) and (5.2).

The average operating temperature of the inner shell is $120^{\circ} \mathrm{F}$, and the NDTT is estimated in Section 4 as $350^{\circ} \mathrm{F}\left(177^{\circ} \mathrm{C}\right)$, it follows from equations (5.1) and (5.2) that $\mathrm{K}_{\mathrm{lc}}=33.4 \mathrm{ksi}$ (in) and $\mathrm{k}_{1 \mathrm{a}}=27.3 \mathrm{ksi}$ (in) $)^{1 / 2}$. This implies that the estimated reference fracture toughness is near the lower "knee" of the fracture toughness transition curve. Also, in this region, the effects of irradiation on the mechanical properties of the steel have largely been saturated (see Figure 5.1).

In the following sections, three critical regions of the inner shell of the lower thermal shield are considered, namely, the region around a beam tube opening and the heat affected zones of the vertical weld region and the welds at the top of the shell. In each case, the available safety factor is computed for hypothetical surface cracks which could be opened out and extended by the operating and residual tensile stresses. The property $\mathrm{K}_{\mathrm{ic}}$ is used as the lower bound fracture toughness of the irradiated material. It should be mentioned that, in the present application, the LEFM methodology and the use of the code values of $\mathrm{K}_{1 \mathrm{c}}$ as a lower bound fracture toughness yields conservative results for two reasons. First, the thickness of the inner shell $(t=0.75$ in. $)$ precludes plane strain conditions (or triaxility of stress) ahead of a crack tip and, second, the material dictates higher fracture toughness than described by the code values of $\mathrm{K}_{\mathrm{lc}}$. In addition, if use is made of Irwin's estimate [Ref. 5-4] of the thickness effects on $\mathrm{K}_{1 \mathrm{c}}$ the critical value of $\mathrm{K}_{1 \mathrm{c}}$ obtained from equation (5.2) can be increased by a factor $=\left(1+1.4 \beta^{2}\right)^{1 / 2}$ where $\beta$ is approximately given by $\beta=0.5$, i.e., by about 1.16 , resulting in $\mathrm{K}_{\mathrm{lc}}=38.80 \mathrm{ksi}(\mathrm{in})^{1 / 2}$. Unless otherwise mentioned, this value of the fracture toughness is used in the remainder of this report when comparing with the crack driving forces.

\subsubsection{Region Around Beam Tube Openings}

Consider a hypothetical crack in a weld region adjoining a beam tube opening with the highest radiation exposure (for example, opening $\mathrm{H9}$ ). The crack is situated in a plane normal to the highest tensile stress in that region so that the crack is opened out by the tensile stress. Since in the inner shell of the lower thermal shield, the stress analysis [Ref. 5-5] yields a circumferential tensile stress on the cooling water side and a compressive stress on the other side (facing the vessel), the most critical crack geometry is a longitudinal surface crack on the cooling water side of the inner shell situated in a plane normal to the maximum tensile stress. Two such crack geometries are investigated: a quarter-elliptical surface crack and a semi-elliptical surface crack.

\section{(a) Quarter Elliptical Surface Crack:}

Consider a quarter elliptical longitudinal crack of depth $=a$ and length $=c, c \geq a$, as shown in Figure 5.2. The depth of the crack is in the radial direction and its length is along the shell surface facing the cooling water. The crack plane is assumed normal to the maximum tensile stress in that region. The stresses across the plate thickness can be linearized and resolved into membrane (constant) and bending components. These stress components give rise to crack driving forces (stress intensity factors) which are responsible for crack extension. The maximum stress intensity factor, $\mathrm{K}_{1}$, 
occurs at the radial point of penetration and is determined from the following formula [see Ref. 5-6 and Appendix A to this report]:

$$
K_{1}=\left(\sigma_{m}+H \sigma_{b}\right) F(\pi a / Q)^{0.5}
$$

where $\sigma_{m}$ and $\sigma_{b}$ are, respectively, the membrane and bending stress components, $Q$ is the flaw shape parameter, and $\mathrm{H}$ and $\mathrm{F}$ are geometry factors. The flaw shape parameter $\mathrm{Q}$ is calculated using the following equation:

$$
Q=1+1.464(a / c)^{1.65}-q_{y}
$$

where $\mathrm{q}_{\mathrm{y}}$ is a plastic zone correction factor calculated using the following equation (Ref. 5-2):

$$
q_{y}=\left[\left(\sigma_{m} M_{m}+\sigma_{b} M_{b}\right) / \sigma_{y s}\right]^{2} / 6
$$

in which $\sigma_{y s}$ is the material yield strength, and $M_{m}$ and $M_{b}$ are respectively, correction factors for membrane and bending stresses. The factors $H$ and $F$ in Equation (5.3) and $M_{m}$ and $M_{b}$ in Equation (5.5) are computed from the following relations:

$$
\begin{aligned}
& H=1+G_{1}(a / t)+G_{2}(a / t)^{2} \\
& G_{1}=-1.22-0.12(a / c) \\
& G_{2}=0.64-1.05(a / c)^{0.75}+0.47(a / c)^{1.5} \\
& F=\left[M_{1}+M_{2}(a / t)^{2}+M_{3}(a / t)^{4}\right]\left[1.08+0.15(a / t)^{2}\right]=M_{m} \\
& M_{1}=1.08-0.03(a / c) \\
& M_{2}=-0.44+1.06 /(0.3+a / c) \\
& M_{3}=-0.5-0.25(a / c)+14.8(1-a / c)^{15} \\
& M_{b}=F H
\end{aligned}
$$

The maximum operating stresses in the inner shell due to dead load, water pressure, seismic load, and thermal expansion, obtained from a detailed submodel of opening $\mathrm{H} 9$, are a circumferential tensile stress of $12.501 \mathrm{ksi}$ on the cooling water surface and a compressive stress of $10.169 \mathrm{ksi}$ on the vessel face [Ref. 5-5]. As per ASME Code, these stresses are linearized into a constant 
(membrane) stress $\sigma_{m}=1.166 \mathrm{ksi}$ and a bending stress $\sigma_{b}=11.335 \mathrm{ksi}$ across the thickness of the inner shell as shown in Figure 5.2. In addition to these stresses, the water pressure $p=0.025 \mathrm{ksi}$ and the circumferential residual stresses due to welding should be added to determine the crack driving forces. Thus, the crack driving force $\left(\mathrm{K}_{1}\right)$ is computed from Equation (5.3) with $\sigma_{m}=1.166+p$ and $\sigma_{b}=11.335+S$, where $p$ is the water pressure and $S$ is the weld-induced residual stress. The weldinduced residual stresses are produced by the restraint of the base metal upon shrinkage of the hot weld when it cools. The final stress distribution depends on the plate thickness, material properties, heat input and arc speed during welding, and the size and number of weld passes. For plates of thicknesses up to one inch, the circumferential residual stress near girth welds is a bending stress of magnitude which can be as high as the yield strength of the base metal [Refs. 5-7 and 5-8].

In the present application, the residual stresses are localized near the weld region and decay very rapidly with the distance from the beam tube opening. The magnitude and distribution of the residual stresses depends on the welding process and materials. The welding procedures specified the submerged arc process except where the metallic arc process was specified. At beam tube openings $\mathrm{H} 1$ through $\bar{H}$, all welds were specified to have full joint penetrations. The working drawings indicate seven passes of single- $V$-groove welds at corner joints near beam tube openings. The distribution of residual stresses is known not to exceed the yield strength of the base metal ( 30 $\mathrm{ksi}$ ). Since the actual distribution of residual stresses cannot be determined from the available information, a conservative assumption would be to consider a tensile axial residual stress $(+S)$ acting on the water surface of the inner shell normal to the crack plane and a compressive stress (-S) on the other side. In general, the magnitude of $S$ varies between 0 and $30 \mathrm{ksi}$ depending on the welding process, preheat treatment, and materials used in the initial construction. However, because the operational stresses and radiation creep have redistributed and relaxed the original residual stress, it is reasonable to estimate the magnitude of $S$ at most as $S=25 \mathrm{ksi}$. In the remainder of this report, the crack driving forces are computed for two values of $S$, namely, 15 and $25 \mathrm{ksi}$.

The crack driving forces $\left(\mathrm{K}_{1}\right)$ for quarter elliptical crack with a/t varying between 0.1 and 0.8 , aspect ratio $c / a=3,2$, and 1 , are given in Tables 5.1 to 5.3. Table 5.1 gives the crack driving forces $\left(\mathrm{K}_{1}\right.$ factors) for normal operational and seismic stresses only $(\mathrm{S}=0)$. Tables 5.2 and 5.3 give the crack driving forces for the operational and seismic stresses and residual stresses $\mathrm{S}=15$ and $25 \mathrm{ksi}$, respectively. It is observed from these three tables that, as the ratio a/t increases, the magnitude of the crack driving force increases, reaches a peak, and then decreases. This variation is typical for members loaded by membrane and bending stresses and cracked on the tension side. It implies that the advancing crack enters a compressive zone which tends to reduce the crack driving force and retards additional extension. For example, in Table 5.3 for cracks with c/a $=1$ and 2 , the $K_{1}$-value for $a / t=0.4$ is lower than that for $a / t=0.3$, while for $c / a=3$, the decline in the values of the $K_{1}$ factor occurs for $a / t$ between 0.4 and 0.5 .

The available factors of safety are computed using the relation:

$$
\text { Factor of Safety }=K_{1 c} / K_{1}
$$


where $\mathrm{K}_{\mathrm{lc}}=38.80 \mathrm{ksi}$ (in) ${ }^{3 / 2}$, which is a lower bound fracture toughness value associated with saturated radiation. For zero residual stress $(S=0)$, the factor of safety for the hypothetical quarterelliptical cracks with aspect ratio of $c / a=3$ varies between 4.28 for $\mathrm{a} / \mathrm{t}=0.5$, and 6.75 for cracks with $\mathrm{a} / \mathrm{t}=0.1$. For $\mathrm{S}=25 \mathrm{ksi}$, which is judged to be the largest value of the current residual stress, the factor of safety for cracks with $\mathrm{c} / \mathrm{a}=3$ varies between 1.45 and 2.03 . For the same residual stress, the available factors of safety for cracks with $c / a=1$ are higher than 2.58 .

(b) Semi-Elliptical Surface Crack:

Consider a hypothetical semi-elliptical surface crack of depth $=a$ and length $\ell=2 c=6 a$ situated in a vertical plane near a beam tube opening as shown in Figure 5.3. As in the previous case, the postulated defect is opened out by the membrane $\left(\sigma_{m}=1.166+p\right)$ and bending $\left(\sigma_{b}=11.335+\right.$ S) stresses.

It is worth mentioning that such a defect is recommended by the ASME Code for evaluating flaws in carbon steel components. The Code formula for calculating the $K_{1}$-factor is [Ref. 5-2]:

$$
K_{1}=\left[\sigma_{m} M_{m}+\sigma_{b} M_{b}\right]\left(\frac{\pi a}{Q}\right)^{1 / 2}
$$

where

$$
\begin{aligned}
& M_{m}=G_{o} \\
& M_{b}=G_{o}-2\left(\frac{a}{t}\right) G_{1}
\end{aligned}
$$

and $G_{0}, G_{1}$ are free surface correction factors given in Table A-3320-1 of Appendix A of Section XI of the ASME Code [Ref. 5-2]. In Equation (5.8), $Q$ is the flaw shape parameter which is given by Equation (5.4). The maximum values of the $K_{1}$ - factor occur at the deepest point of penetration of the surface crack. Using $\sigma_{\mathrm{m}}=1.191 \mathrm{ksi}, \sigma_{\mathrm{b}}=11.335+\mathrm{S} \mathrm{ksi}$ and $\mathrm{S}=0,15$ and $25 \mathrm{ksi}$, the computed values of the $K_{1}$ - factor (crack driving force) for a crack aspect ratio of $c / a=3$ (i.e., crack length $\ell$ $=2 c=6 a)$ are shown in Table 5.4. Here again it is observed that as the ratio a/t increases, the crack driving force increases, reaches a peak, and then declines in magnitude because the leading edge of

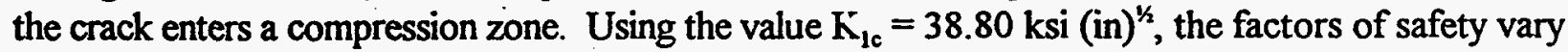
between 1.61 (for $a / t=0.4$ and $S=25 k s i)$ and $4.79($ for $a / t=0.4$ and $S=0)$.

\subsubsection{Region Near the Longitudinal Weld}

The inner water-retaining shell was constructed from a single piece of steel plate with a vertical seam positioned in an area of minimum stress and minimum radiation exposure. The weld 
occupies a region approximately lying in the middle of two beam tube openings. A double-V groove weld was used to form a butt joint. Section 10 of the original engineering report (HFBR, FSAR, Page 10) indicates that .... "The entire length of all welds and weld repairs was radiographed as the geometry permitted. In places where radiography was unsatisfactory, dye penetrant checks of the welds were made". Near the vertical weld, the fluence due to the combined effects of neutrons and gammas is estimated at $1 / 3 \times 2.4 \times 10^{19} \mathrm{n} / \mathrm{cm}^{2}(E>1 \mathrm{MeV})$ [Ref. 4-14]. Estimate of the NDTT based on extrapolation of Chow's results at $5.5 \times 10^{18} \mathrm{n} / \mathrm{cm}^{2}$ would then be $250^{\circ} \mathrm{F}$. It follows that the fracture toughness of the material in this region can be conservatively estimated as $K_{1 c}=41.20$ ksi (in) $)^{1 / 2}$.

Consider the heat affected zones (HAZ) of the longitudinal weld region. In this region, the stress report [Ref. 5-9] indicates a maximum vertical stress of $+4.036 \mathrm{ksi}$ on the water side and -0.089 $\mathrm{ksi}$ on the vessel side of the shell. The corresponding hoop stresses are $+4.452 \mathrm{ksi}$ on the vessel side and $+1.835 \mathrm{ksi}$ on the water side. These stresses are lower than those operating near beam tube opening H9. Hence, using similar residual stresses, i.e., bending type with maximum magnitude $S$ $=25 \mathrm{ksi}$, a postulated circumferential or axial semi-elliptical crack in the HAZ of the weld region should experience lower $\mathrm{K}_{1}$ - values than those computed in Table 5.4, and therefore the calculations need not be repeated. In the present application, the inner shell may be considered as two flat plates welded together and the vertical residual stress (parallel to the weld) has a constant distribution through the thickness [Ref. 5-8]. In that case a residual stress gives rise to large crack driving forces for circumferential semi-elliptical surface cracks. A semi-elliptical circumferential crack in the HAZ of the longitudinal weld region is shown in Figure 5.4. The hypothetical crack is located on the water side of the inner shell and opened out by the operating vertical stresses, water pressure, and residual stresses. Assuming a constant distribution of vertical residual stress in the HAZ of the vertical weld, the $\mathrm{K}_{1}$ - factors have been computed and the results appear in Table 5.5. For cracks with $\mathrm{a} / \mathrm{t}=0.3$ and length $\ell=6 \mathrm{a}=1.35$ inch, the factor of safety is 1.47 for $\mathrm{S}=25 \mathrm{ksi}$.

Finally, the possibility of opening up of a partial joint penetration groove weld that was used to form the inner shell of the shield needs to be investigated. The working drawings indicates a possibility that a partial joint was used in the original construction. For such a weld a natural two dimensional crack in plane strain conditions is formed between the two v-groove welds as shown in the sketch of Figure 5.5. The geometry indicates a finite-width plate containing a through-thickness crack of length $=2 \mathrm{a}$. Such a crack is opened out by the circumferential operating and residual stresses. The crack driving force for such a crack is given by the formula [Ref. 5-10]:

$$
K_{1}=\left[\frac{2 t}{\pi a} \tan (\pi a / 2 t)\right]^{1 / 2} \sigma(\pi a)^{1 / 2}
$$

where $t$ is the thickress of the plate $(t=0.75$ in), $2 a=$ length of crack, and $\sigma$ is the circumferential stress. Assuming a constant residual stress, $\mathrm{S}=25 \mathrm{ksi}$, the crack driving forces for cracks with length varying in the range 0.25 to 0.45 inch are given in Table 5.6. In this case, assuming $K_{1 C}=41.20 \mathrm{ksi}$ $\left(\right.$ in) ${ }^{1 / 2}$, the factors of safety are greater than 1.47 . 


\subsubsection{Regions Near the Welds at the Top of the Lower Thermal Shield}

At the upper end of the inner cylinder of the lower thermal shield there are welds which seal the cooling water passages. In this region, i.e., near the bottom of the upper thermal shield, the material of the cylinder is thinned down to $3 / 8$ inch to allow acceptable deflection and stresses under thermal expansion due to reactor startup. Welds were used to join the $3 / 4$ inch to the $3 / 8$ inch plates. Weld designated (W1) in the stress report [Ref. 5-9] develops the critical stress which is in the hoop direction. The magnitude is $1.285 \mathrm{ksi}$ on the cooling water side and $3.869 \mathrm{ksi}$ on the vessel side. Linearizing these stresses results in $\sigma_{m}=2.577 \mathrm{ksi}$ and $\sigma_{b}=1.292 \mathrm{ksi}$. To these one must residual stress which is of bending type of maximum magnitude $S=25 \mathrm{ksi}$. The crack is assumed on the vessel side in the heat affected zone of the critical weld. For a semi-elliptical axial crack, the factor $\mathrm{K}_{1}$ is computed from Equations (5.8) and (5.9) and the results appear in Table 5.7. It is clear that for $\mathrm{K}_{\mathrm{lc}}=41.20 \mathrm{ksi}(\mathrm{in})^{1 / 2}$, the minimum factor of safety is 3.05 . 


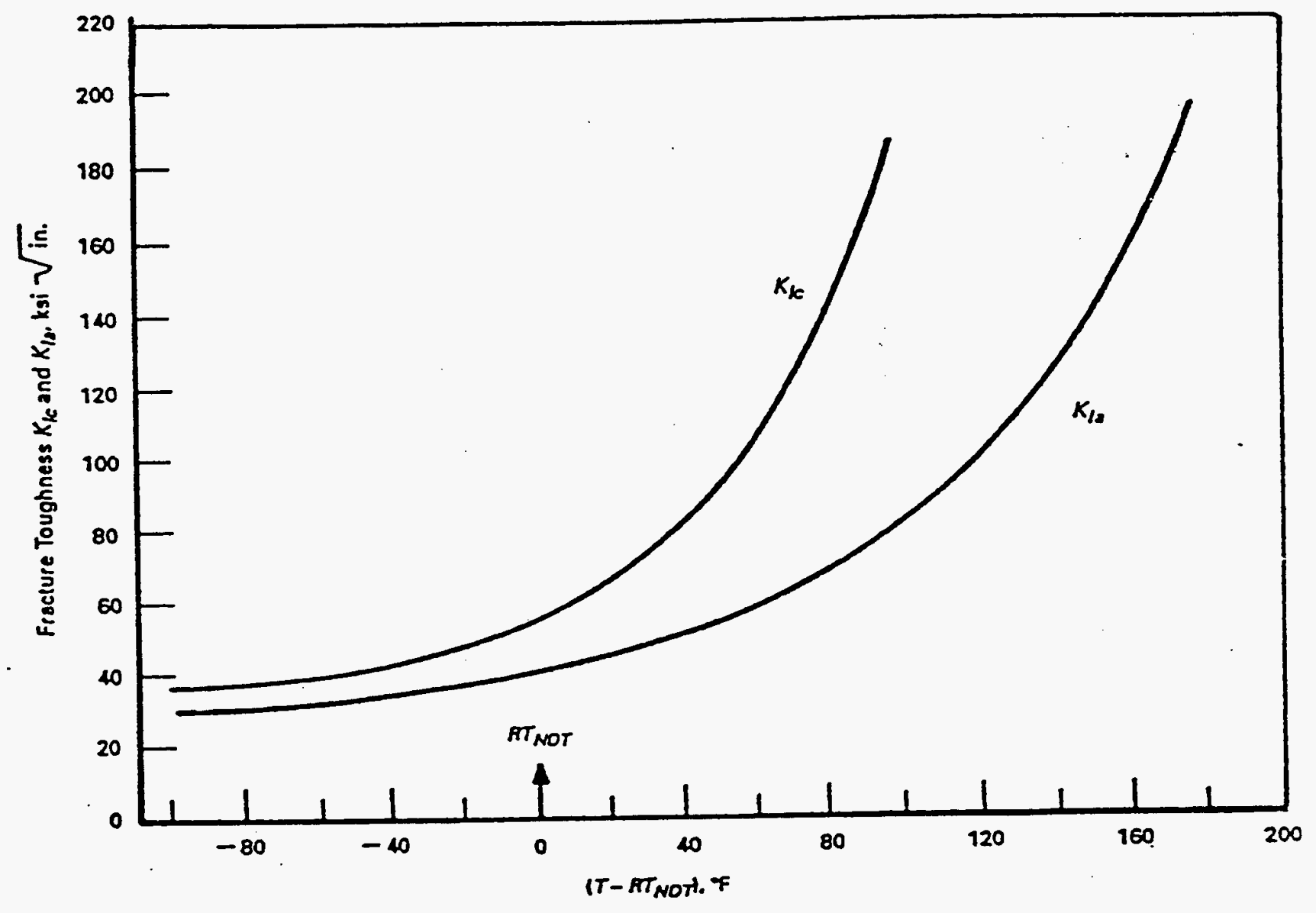

Figure 5.1 Lower Bound $\mathrm{K}_{1 \mathrm{c}}$ and $\mathrm{K}_{1 \mathrm{a}}$ Test Data for Carbon Steel (ASME Code) 


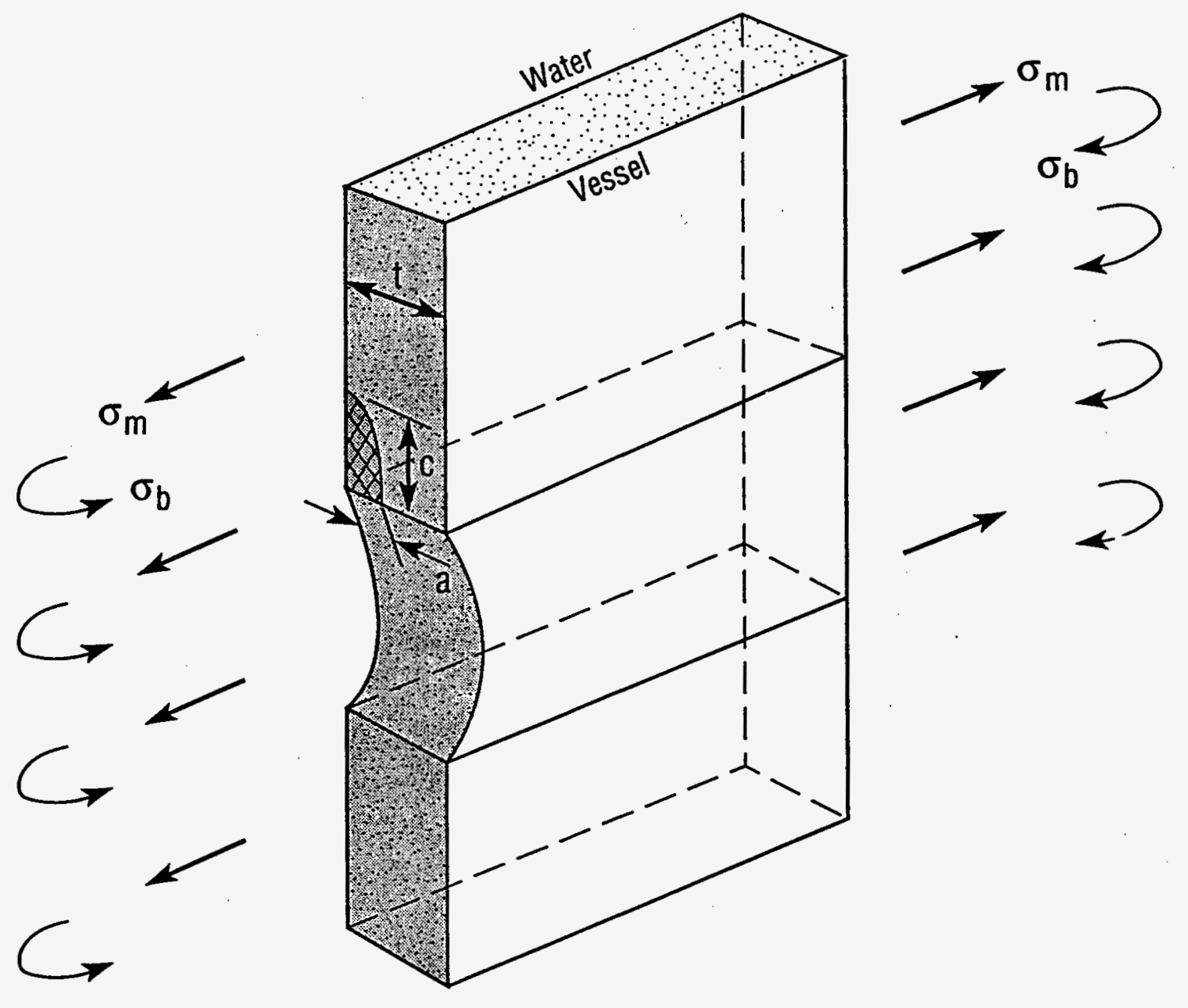

Figure 5.2 A Quarter-Elliptical Surface Crack at a Beam Tube opening

21 


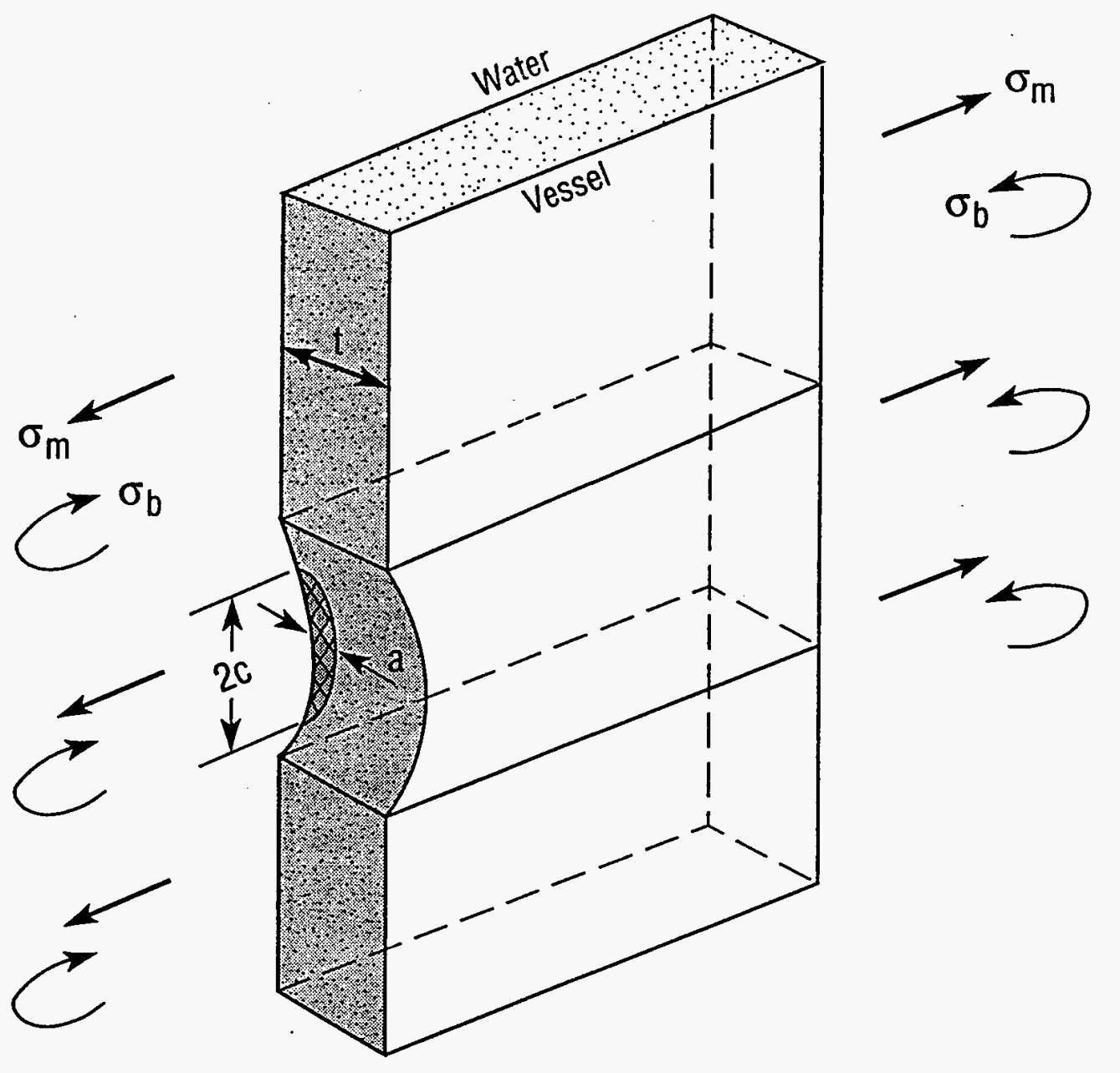

Figure 5.3 A Semi-Elliptical Surface Crack in a Vertical Plane Near a Beam Tube Opening.

22 


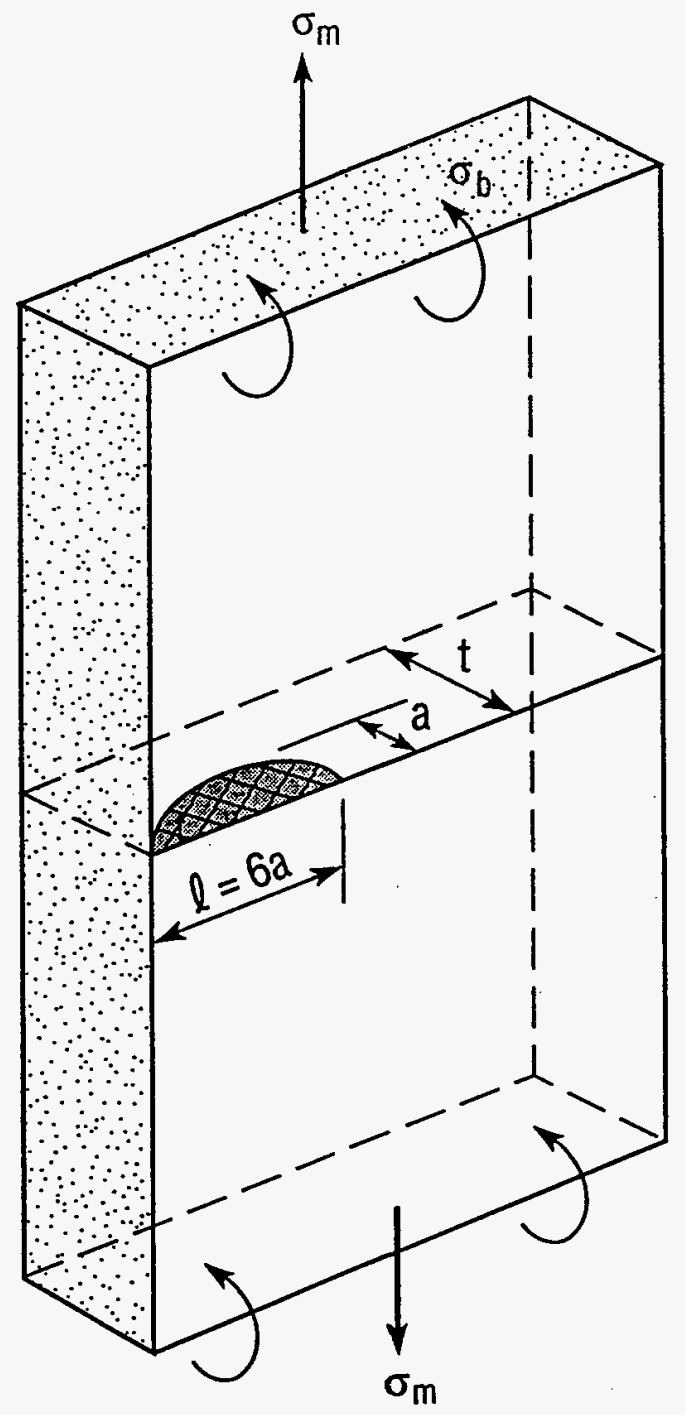

Figure 5.4 A semi-Elliptical Circumferential Crack in the HAZ of the Longitudinal Weld Region 


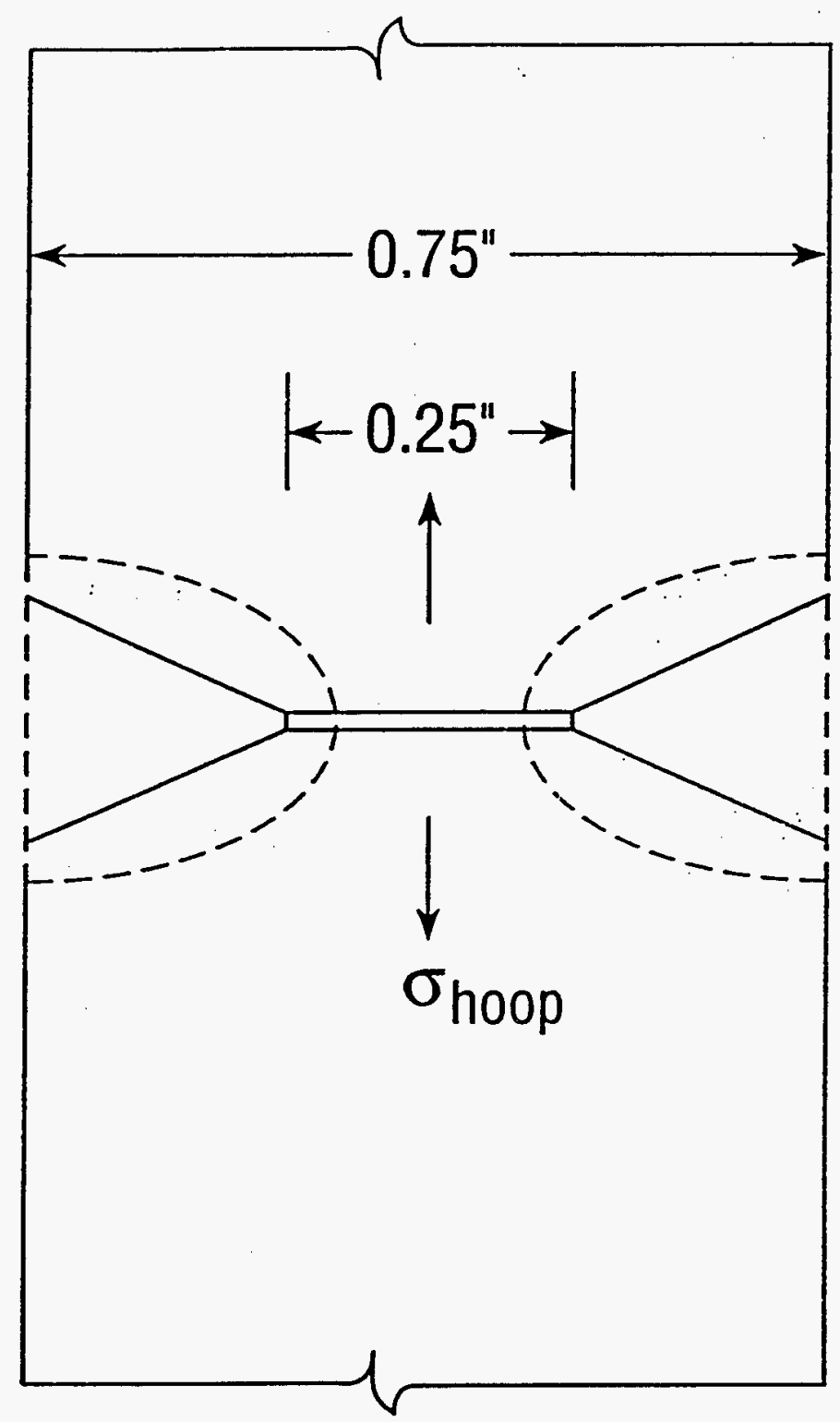

Figure 5.5 A Two-Dimensional Crack Between Two V-Grooves in a Weld Butt Joint 
Table 5.1

Stress intensity factors $\left(\mathrm{K}_{1}-\mathrm{ksi} \sqrt{\mathrm{in}}\right)$ for hypothetical quarter-elliptical surface cracks near beam tube opening

(Residual Stress $S=0$ )

\begin{tabular}{|c|c|c|c|c|}
\hline $\begin{array}{c}\text { Crack Depth } \\
\mathbf{a} \text { (inch) }\end{array}$ & $\mathbf{a / t}$ & $\mathbf{c / a}=\mathbf{3}$ & $\mathbf{c / a}=\mathbf{2}$ & $\mathbf{c / a}=\mathbf{1}$ \\
\hline 0.075 & 0.1 & 5.75 & 5.22 & 3.90 \\
\hline 0.150 & 0.2 & 7.41 & 6.62 & 4.83 \\
\hline 0.775 & 0.3 & 8.35 & 7.28 & 5.09 \\
\hline 0.300 & 0.4 & 8.88 & 7.47 & 4.90 \\
\hline 0.375 & 0.5 & 9.07 & 7.26 & 4.33 \\
\hline 0.450 & 0.6 & 8.89 & 6.56 & 3.42 \\
\hline 0.525 & 0.7 & 8.30 & 5.59 & 2.22 \\
\hline 0.600 & 0.8 & 7.23 & 4.11 & 0.82 \\
\hline
\end{tabular}

$\mathrm{t}=$ plate thickness $=0.75$ inch

$\mathrm{c}=$ crack length $=3 \mathrm{a}$ 
Table 5.2

Stress intensity factors $\left(K_{1}-k s i \sqrt{ }\right.$ in) for hypothetical quarter-elliptical surface cracks near beam tube opening

(Residual Stress $\mathrm{S}=15 \mathrm{ksi}$ )

\begin{tabular}{|c|c||c|c|c|}
\hline $\begin{array}{c}\text { Crack Depth } \\
\mathbf{a} \text { (inch) }\end{array}$ & $\mathbf{a} / \mathbf{t}$ & $\mathbf{c / a}=\mathbf{3}$ & $\mathbf{c / a}=\mathbf{2}$ & $\mathbf{c / a}=\mathbf{1}$ \\
\hline 0.075 & 0.1 & 13.22 & 11.87 & 8.71 \\
\hline 0.150 & 0.2 & 16.71 & 14.78 & 10.60 \\
\hline 0.225 & 0.3 & 18.47 & 15.95 & 10.95 \\
\hline 0.300 & 0.4 & 19.24 & 15.99 & 10.28 \\
\hline 0.375 & 0.5 & 19.15 & 15.09 & 8.76 \\
\hline 0.450 & 0.6 & 18.17 & 13.08 & 6.49 \\
\hline 0.525 & 0.7 & 16.21 & 10.42 & 3.58 \\
\hline 0.600 & 0.8 & 13.22 & 6.66 & 0.31 \\
\hline
\end{tabular}

$$
\begin{gathered}
\mathrm{t}=\text { plate thickness }=0.75 \text { inch } \\
\mathrm{c}=\text { crack length }=3 \mathrm{a}
\end{gathered}
$$


Table 5.3

Stress intensity factors $\left(K_{1}-k s i \sqrt{\text { in }}\right)$ for hypothetical quarter-elliptical surface cracks near beam tube opening

(Residual Stress $\mathrm{S}=25 \mathrm{ksi}$ )

\begin{tabular}{|c|c||c|c|c|}
\hline $\begin{array}{c}\text { Crack Depth } \\
\mathbf{a} \text { (inch) }\end{array}$ & $\mathbf{a} / \mathbf{t}$ & $\mathbf{c / a}=\mathbf{3}$ & $\mathbf{c} / \mathbf{a}=\mathbf{2}$ & $\mathbf{c} / \mathbf{a}=\mathbf{1}$ \\
\hline 0.075 & 0.1 & 19.15 & 16.98 & 12.17 \\
\hline 0.150 & 0.2 & 23.83 & 20.84 & 14.67 \\
\hline 0.225 & 0.3 & 26.02 & 22.22 & 15.02 \\
\hline 0.300 & 0.4 & 26.79 & 22.03 & 13.96 \\
\hline 0.375 & 0.5 & 26.36 & 20.34 & 11.76 \\
\hline 0.450 & 0.6 & 24.68 & 17.35 & 8.54 \\
\hline 0.525 & 0.7 & 21.66 & 13.68 & 4.49 \\
\hline 0.600 & 0.8 & 17.26 & 8.37 & $-\cdots$ \\
\hline
\end{tabular}

$\mathrm{t}=$ plate thickness $=0.75$ inch

$\mathrm{c}=$ crack length $=3 \mathrm{a}$ 
Table 5.4

Stress intensity factors $\left(K_{1}-k s i \sqrt{ }\right.$ in) for hypothetical semi-elliptical axial cracks near beam tube opening

\begin{tabular}{|c|c|c|c|c|}
\hline \multirow{2}{*}{$\begin{array}{l}\text { Crack Depth } \\
\text { a (inch) }\end{array}$} & \multirow{2}{*}{$\mathbf{a} / \mathbf{t}$} & \multicolumn{3}{|c|}{ Residual Stress S } \\
\hline & & $\mathrm{S}=0 \mathrm{ksi}$ & $S=15 \mathrm{ksi}$ & $\mathrm{S}=25 \mathrm{ksi}$ \\
\hline 0.075 & 0.1 & 5.41 & 12.34 & 17.72 \\
\hline 0.150 & 0.2 & 6.92 & 15.52 & 21.97 \\
\hline 0.225 & 0.3 & 7.73 & 17.00 & 23.80 \\
\hline 0.300 & 0.4 & 8.10 & 17.46 & 24.18 \\
\hline 0.375 & 0.5 & 8.08 & 16.97 & 23.23 \\
\hline 0.450 & 0.6 & 7.57 & 13.35 & 20.73 \\
\hline 0.525 & 0.7 & 6.43 & 12.30 & 16.29 \\
\hline 0.600 & 0.8 & 4.44 & 7.37 & 9.34 \\
\hline
\end{tabular}

$\mathrm{t}=$ plate thickness $=0.75$ inch

$\ell=$ crack length $=6 a$ 
Table 5.5

Stress intensity factors $\left(K_{1}-k s i \sqrt{ }\right.$ in) for hypothetical semi-elliptical circumferential crack near longitudinal (vertical) weld region

\begin{tabular}{|c|c||c|c|c|}
\hline \multirow{2}{*}{$\begin{array}{c}\text { Crack Depth } \\
\text { a (inch) }\end{array}$} & $\mathbf{a} / \mathbf{t}$ & $\mathbf{S = 0 ~ k s i}$ & $\mathbf{S}=\mathbf{1 5} \mathbf{~ k s i}$ & $\mathbf{S}=\mathbf{2 5} \mathbf{~ k s i}$ \\
\hline 0.075 & 0.1 & 1.83 & 9.34 & 15.02 \\
\hline 0.150 & 0.2 & 2.50 & 13.49 & 21.86 \\
\hline 0.225 & 0.3 & 3.01 & 17.20 & 28.10 \\
\hline
\end{tabular}

$\mathrm{t}=$ plate thickness $=0.75$ inch

$\ell=$ crack length $=6 a$ 
Table 5.6

Stress intensity factors $\left(\mathrm{K}_{1}-\mathrm{ksi} \sqrt{\mathrm{in}}\right)$ for a two-dimensional crack between two $\mathrm{V}$-grooves in a weld butt joint (Residual Stress $S=25 \mathrm{ksi}$ )

\begin{tabular}{|c|c|c|}
\hline $\begin{array}{c}\text { Crack Length } \\
\text { 2a (inches) }\end{array}$ & $\mathbf{( 2 a ) / t}$ & $\mathbf{K}_{\mathbf{1}}-\mathbf{k s i} \sqrt{\mathbf{i n}}$ \\
\hline 0.25 & 0.333 & 18.52 \\
\hline 0.30 & 0.400 & 20.77 \\
\hline 0.35 & 0.467 & 23.13 \\
\hline 0.40 & 0.533 & 25.67 \\
\hline 0.45 & 0.600 & 28.00 \\
\hline
\end{tabular}

$I=$ plate thickness $=0.75$ inch 
Table 5.7

Stress intensity factors $\left(K_{1}-k s i \sqrt{\text { in }}\right)$ for an axial semi-elliptical crack near the top welds

\begin{tabular}{|c|c||c|c|c|}
\hline \multirow{2}{*}{$\begin{array}{c}\text { Crack Depth } \\
\text { a (inch) }\end{array}$} & $\mathbf{a} / \mathbf{t}$ & $\mathbf{S}=\mathbf{0} \mathbf{~ k s i}$ & $\mathbf{S}=\mathbf{1 5} \mathbf{~ k s i}$ & $\mathbf{S}=\mathbf{2 5} \mathbf{~ k s i}$ \\
\hline 0.0375 & 0.1 & 1.26 & 5.88 & 9.27 \\
\hline 0.0750 & 0.2 & 1.77 & 7.57 & 11.75 \\
\hline 0.1125 & 0.3 & 2.18 & 8.50 & 13.00 \\
\hline 0.1500 & 0.4 & 2.56 & 9.00 & 13.52 \\
\hline 0.1875 & 0.5 & 2.92 & 9.09 & 13.37 \\
\hline 0.2250 & 0.6 & 3.24 & 8.68 & 12.41 \\
\hline 0.2625 & 0.7 & 3.48 & 7.62 & 10.42 \\
\hline
\end{tabular}

$\mathrm{t}=$ plate thickness $=0.375$ inch

$$
\ell=\text { crack length }=6 \mathrm{a}
$$




\section{CONCLUSIONS AND RECOMMENDATIONS}

Based on the evaluations carried out in this report, the following conclusions can be drawn:

(a) Corrosion is not a significant degradation mechanism for the lower thermal shield (LTS) because the water chemistry is controlled during operation and shutdown.

(b) Portions of the LTS closest to the reactor (i.e., innermost water-retaining cylinder) have been embrittled by irradiation. This implies a loss in the fracture toughness of the material (loss in the ability of the material to resist crack extension). The fracture toughness of an irradiated carbon steel material is usually indexed against a transition temperature. In a qualitative sense, at the nil-ductility transition temperature (NDTT), the material changes its fracture behavior from ductile to brittle. Because of exposure to neutron and gamma rays, the estimated NDTT near beam tube openings is about $350^{\circ} \mathrm{F}$, which is well above the normal operating temperature of $120^{\circ} \mathrm{F}$. It follows that the highly irradiated material (including the weld material) near beam tube openings is operating in the lower-shelf region of the Charpy impact curve (below the NDTT).

(c) A fracture mechanics evaluation using the methodology of the ASME Boiler and Pressure Vessel Code indicates that the combined effects of the operating and (conservatively estimated) residual stresses in the highly irradiated regions of the LTS shows a large factor of safety (>1.5) against propagation of credible hypothetical surface cracks. Since the effects of irradiation on the mechanical properties of the material have largely been saturated, no significant further degradation in the material is expected, and this conclusion can be safely extrapolated to the expected lifetime of the new reactor vessel (20 - 30 years).

The following recommendations should be considered:

(a) The water chemistry controls on the LTS coolant should be formalized for both operational and shutdown conditions.

(b) In case the HFBR vessel is replaced, extreme care should be taken to avoid impact loads on the LTS during disassembly and removal of the existing vessel and insertion of the new vessel. 


\section{REFERENCES}

2-1 Skonieczny, J.F., Reactor Division Calculation \#96-17, "Thermal Shield Stress Analysis," Rev. 0, 1996.

2-2 Timoshenko, S.P. and Goodier, J.N., "Theory of Elasticity," Third Edition, McGraw-Hill, p. 449, 1970.

3-1 Gharabegie, G., CBNL Reactor Division, Memorandum to J.R. Weeks, “Aging Degradation Analysis in the HFBR Thermal Shield," August 21, 1995, with attached Memorandum from Karol, R., "Calculated Thermal Shield Fast Neutron ( $\mathrm{E}>0.1 \mathrm{MeV}$ ) and High Energy Gammas (E> 1.0 MeV) Fluence per MWD of Operation."

3-2 Preban, A.G., "Corrosion of Carbon Steels," in ASM Handbook, 9th Edition, Vol. 13 “Corrosion", pp. 509-530, ASM International, 1987.

3-3 Divine, J.R., (Chem-Nuclear), discussions at 15th Tank Structural Integrity Workshop, Richland, WA, August 1995; data cited in the report of the workshop.

3-4 Cragnolino, G., Czajkowski, C. (BNL) and Shack, W.J. (ANL), "Review of ErosionCorrosion in Single-Phase Flow in Nuclear Power Plants," NUREG/CR-5156, April 1988.

4-1 Chow, J.G.Y., Montag, M., Jones, R. and Hare, J., "HFBR Surveillance Program," Metallurgy Memo 1159, April 19, 1968.

4-2 Nanstad, R.K., Iskander, S.K., Rowcliffe, A.F., Corwin, W.R. and Odette, G.R., "Efffects of $50^{\circ} \mathrm{C}$ Surveillance and Test Reactor Irradiations on Ferritic Pressure Vessel Steel Embrittlement," Effects of Radiation on Materials, 14th International Symposium, Vol. II, ASTM STP - 1046. ASTM, Philadelphia, PA, pg. 5-29, 1990.

4-3 Remec, I. and Kam, F.B.K. (ORNL), "HFIR Steels Embrittlement: The Possible Effect of Gamma Field Contribution," paper presented at 17th Symposium on Effects of Radiation on Materials, Sun Valley, ID, Abstract \#41 - in press, ASTM, Philadelphia, PA, June 1994.

4-4 Alexander, D.E. and Rehn, L.E. (ANL), “Analysis of Gamma Ray Displacement Damage in Light Water Reactor Pressure Vessels," paper presented at the 7th International Symposium on Environmental Degradation of Materials in Nuclear Power Systems - Water Reactors, Breckenridge, CO, August 1995. Proceedings to be published by NACE, Houston, TX, 1995. Also, discussion with D. Alexander at the conference.

4-5 Chow, J.G.Y., Singer, R. and Montag, M., "HFBR Surveillance Program," Metallurgy Memo 1141, June 14, 1967. 
4-6 Ludewig, H. and Aronson, A.L., "HFBR Thermal Shield Heating and Flux Estimates," Memorandum to Reactor Division, 1996.

4-7 Chow, J.G.Y. and Jones, R., "Review of HFBR Surveillance Program," Memo to Gurinsky, D.H., July 12, 1976 attached to Reference 4-8.

4-8 Gurinsky, D.H., "J. Chow's HFBR Surveillance Memo," memo to R.W. Powell, July 27, 1976.

4-9 Steele, L.E. and Hawthorne, J.R., "Effect of Irradiation Temperature on Neutron-Induced Changes in Notch Ductility of Pressure Vessel Steels," NRL-5629, 1961; MTR data at $95^{\circ} \mathrm{C}$ cited by Nanstad et al.

4-10 Alekseyenko, N.N., Amayev, A.D., Gorynin, I.V. and Nikolayev, V.A., "Radiation Damage to Steel of Water-Moderated, Water-Cooled Reactor Vessels," Energuizdat 1981 [English Translation U.D.C. 621.039.531].

4-11 Canonico, D.A., "Stress-Relief Heat Treating of Steel," in ASM Handbook, 9th Edition, Vol. 4, "Heat Treating," pp. 3-5, ASM International, 1981.

4-12 Farrell, K., Mahmood, S.T., Stoller, R.E. and Mansur, L.K., J. Nuclear Materials, pp. 268281, 210 (1994).

4-13 Farrell, K. and Grossbeck, M. (ORNL), Private Communications, May 1996.

4-14 Ludewig, H., Private Communication, June 1996.

4-15 Farrell, K. (ORNL), Private Communication, June 25, 1996.

4-16 Farrell, K., Stoller, R.E. and Mansur, L.K., "The Effect of Thermal Neutrons on Tensile Properties in Ferritic Steels Irradiated at Low Temperature," paper presented at 18th ASTM Symposium on the Effects of Radiation on Materials, June 25, 1996.

5-1 ASME Boiler and Pressure Vessel Code, Section III, Division 1, Appendix G, "Protection Against Nondestructive Failure," American Society of Mechanical Engineers, New York, pp. 293-301, 1995.

5-2 ASME Boiler and Pressure Vessel Code, Section XI, "Rules for Inservice Inspection of Nuclear Power Plant Components," Appendix A, "Analysis of Flaws," American Society of Mechanical Engineers, New York, pp. 355-376, 1995. 
5-3 E 208-87, "Standard Test Method for Drop-Weight Test to Determine Nil-Ductility Transition Temperature of Ferritic Steels," American Society of Testing and Materials, Philadelphia, 1987.

5-4 Irwin, G.R., "Crack-Toughness Testing of Strain-Rate Sensitive Materials," Journal of Engineering for Power, Transactions of the ASME, Series A, Volume 86, p. 444, 1964.

5-5 Skonieczny, J.F., "Final Results for the Stress Analysis of HFBR Thermal Shield (60 MW H9 Extended at Cylinder 4/H9 Sleeve Juncture," Memorandum to K. Bandyopadhyay, Brookhaven National Laboratory, February 17, 1997.

5-6 Anderson, T.L., Fracture Mechanics, second edition, CRC Press, Inc., Boca Raton, Florida, 1995.

5-7 Rybicki, E.F. Stonesifer, R.B. and Olson, R.J., "Stress Intensity Factors due to Residual Stresses in Thin-Walled Girth-Welded Pipes," ASME Journal of Pressure Vessel Technology, Volume 103, pp. 66-75, February 1981.

5-8 Nordell, W.J. and Hall, W.J., "Two Stage Fracturing in Welded Mild Steel Plates," Weld. J. Research Supplement, Blume 44, No. 3, 124-S to 134-S, 1965.

5-9 Skonieczny, J.F., Reactor Division Draft Calculation 96-17, "HFBR Thermal Shield Stress Analysis, "Memorandum to K. Bandyopadhyay, Brookhaven National Laboratory, November 25, 1996.

5-10 Barsom, J.H. and Rolfe, S.T., "Fracture and Fatigue Control in Structures," 2nd Edition, Prentice-Hall, 1987. 


\section{APPENDIX A}

This appendix contains Page 630 of Reference 5-6 which gives the formula for the $\mathrm{K}_{1}$ - factor used in Section 5.1.1 (a).

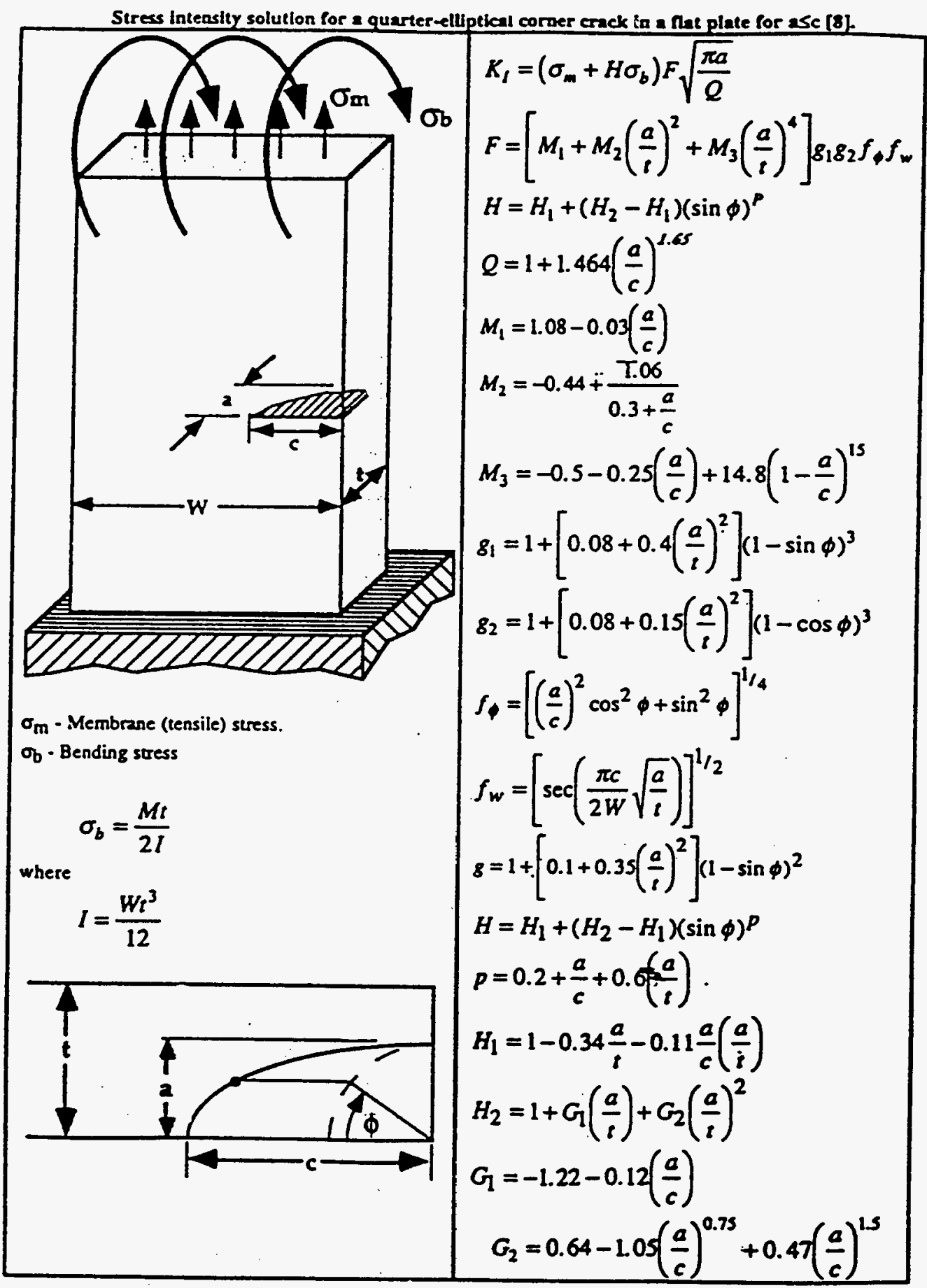


Report Number (14)BNL- -65233

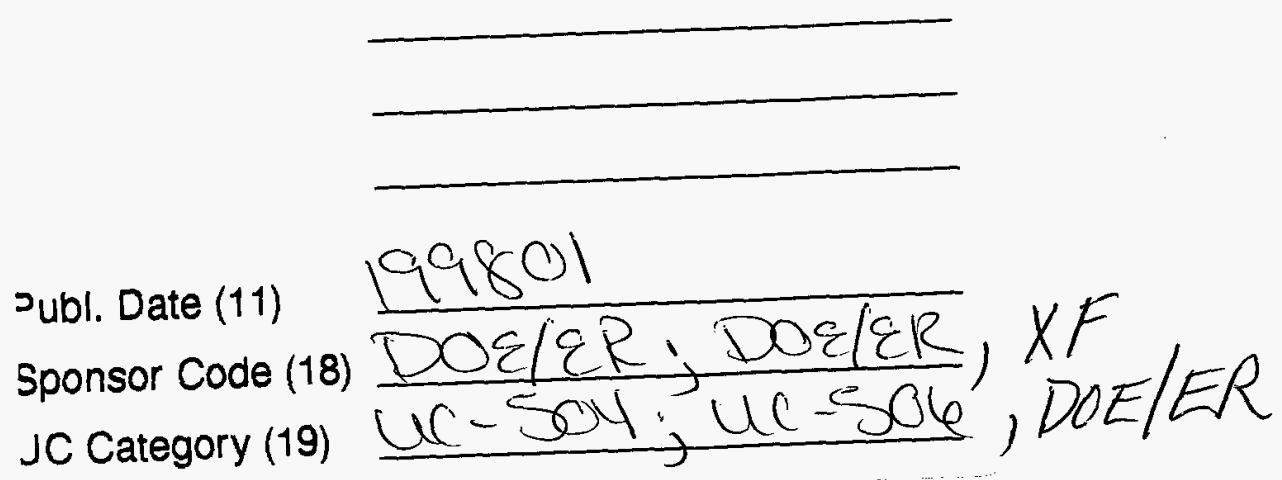

